\title{
Stability of VLBI, SLR, DORIS, and GPS positioning
}

\author{
M. Feissel-Vernier ${ }^{1}$, O. de Viron ${ }^{2}$, and K. Le Bail ${ }^{3}$ \\ ${ }^{1}$ Observatoire de Paris/SYRTE and Institut Géographique National/LAREG, 61 Avenue de l'Observatoire, 75014 Paris, France \\ ${ }^{2}$ Institut de Physique du Globe de Paris/Géodésie et Gravimétrie, and Université Paris 7, 4 Place Jussieu, Case 89, 75252 Paris Cedex 05, France \\ ${ }^{3}$ IGN/LAREG and Observatoire de la Côte d'Azur/GEMINI, 8 Avenue Blaise Pascal, 77455 Marne la Vallée Cedex, France
}

(Received October 3, 2006; Revised February 15, 2007; Accepted April 13, 2007; Online published June 27, 2007)

\begin{abstract}
The residual signal in VLBI, SLR, DORIS and GPS station motion, after a linear trend and seasonal components have been removed, is analysed to investigate site-specific and technique-specific error spectra. The study concentrates on 60 sites with dense observation history by two or more space geodetic techniques. Statistical methods include the Allan variance analysis and the three-cornered hat algorithm. The stability of time-series is defined by two parameters, namely the Allan deviation for a one-year sampling time (noise level) and the slope of the Allan variance graph with its spectral interpretation (noise type). The site-specific noise level is found to be in the range $0.5-3.5 \mathrm{~mm}$ in either horizontal direction and $1-4.5 \mathrm{~mm}$ in height for most sites. The distribution of site-specific noise type includes both white noise and flicker noise. White noise is predominant in the East direction. Both types of noise are found in the North direction, with no particular geographical clustering. In the Up direction, the Northern hemisphere sites seem to be split in two large geographical sectors characterised either by white noise or by flicker noise signatures. Technique-specific noise characteristics are estimated in several ways, leading to a white noise diagnostic for VLBI and SLR in all three local directions. DORIS has also white noise in the horizontal directions, whereas GPS has a flicker noise spectrum. The vertical noise spectrum is indecisive for both DORIS and GPS. The three-dimensional noise levels for the one-year sampling time are $1.7 \mathrm{~mm}$ for VLBI, $2.5 \mathrm{~mm}$ for SLR, $5.2 \mathrm{~mm}$ for DORIS, and $4.1 \mathrm{~mm}$ for GPS. For GPS, the long-term analysis homogeneity has a strong influence. In the case of a test solution reanalysed in a fully consistent way, the noise level drops to the VLBI level in horizontal and to the SLR level in vertical. The three-dimensional noise level for a one-year sampling time decreases to $1.8 \mathrm{~mm}$. In addition, the percentage of stations with flicker noise drops to only about $20 \%$ of the network.
\end{abstract}

Key words: Reference frames, station positions, station stability, Allan variance, three-cornered hat.

\section{Introduction}

Since the start of the International Earth Rotation and Reference Systems Service (IERS) in the late 1980's, the International Terrestrial Reference Frame (ITRF) was provided as a combination of sets of station coordinates and linear velocities. The last issue of this series of reference frames, ITRF2000 (Altamimi et al., 2002; Boucher et al., 2004), is based on sets of station positions and velocities from four global space geodetic techniques, VLBI, SLR, DORIS, and GPS. Meanwhile, many analysis groups started to develop time-series of station positions observed with these techniques. Good quality series go back to the early or mid-1990's, depending on the technique. The use of these time-series is expected to allow a better geophysical interpretation of the observed motions. Taking advantage of the availability of these new data, the current issue of the ITRF, ITRF2005, is the first attempt to define a multi-technique terrestrial reference frame (TRF) based on time series (Altamimi and Collilieux, 2007). In this context, knowing the quality of station motion measurements, in particular their long term stability for each site and each

Copyright (c) The Society of Geomagnetism and Earth, Planetary and Space Sciences (SGEPSS); The Seismological Society of Japan; The Volcanological Society of Japan; The Geodetic Society of Japan; The Japanese Society for Planetary Sciences; TERRAPUB technique, is necessary for insuring the best possible internal consistency and time stability of the combined terrestrial reference frame.

The purpose of this article is to contribute to this knowledge, by considering the statistical properties of the timeseries of site positions observed with two or more global techniques. Linearity of three-dimensional linear station motions remains the basic hypothesis for the control of the time evolution of the terrestrial reference frame, as well as in most uses of space geodetic positioning. The horizontal component is primarily related to tectonic plate motion, while the height component is associated with local or regional uplift or subsidence. In this context, time-series of station positions are particularly useful to understand the residual signal (that we will call "non-linear motion" here below), that may be related to local geophysical phenomena, instrumentation, or to the analysis strategies and modelling. In many cases, the non-linear motion includes a seasonal component. Residual annual signatures that may exist are considered as medium-term noise having no influence on the longer term stability. We will therefore study station stability via the spectral signature and the level of noise of their non-linear, non-seasonal motion.

The data available for this study and their pre-processing are described in Section 2, with more details in the Ap- 
Table 1. Start and end dates, and duration of time-series of station coordinates, numbers of collocation sites for each technique and per pair of techniques, separately for two-technique and three- or four-technique sites. Only one physically meaningful site, Greenbelt, hosts the four techniques. See the Appendix for details per site and per station.

\begin{tabular}{|c|c|c|c|c|c|c|c|c|}
\hline \multicolumn{2}{|c|}{ Technique } & \multirow[t]{3}{*}{ Data span } & \multicolumn{2}{|c|}{ Duration } & \multicolumn{4}{|c|}{ Sites with pair of techniques } \\
\hline & \multirow{2}{*}{$\begin{array}{c}\text { Sites } \\
\text { (Total) }\end{array}$} & & Min & $\operatorname{Max}$ & S L R & & RIS & G P S \\
\hline & & & \multicolumn{2}{|c|}{ (years) } & $23-4$ & 2 & $3-4$ & $23-4$ \\
\hline VLBI & 26 & $1990.0-2005.8$ & 3.5 & 15.8 & & - & 7 & 1512 \\
\hline SLR & 20 & $1993.0-2005.0$ & 3.6 & 12.0 & - & 2 & 4 & 12 \\
\hline DORIS & 30 & $1994.0-2006.0$ & 3.2 & 12.1 & & & & 1910 \\
\hline GPS & 56 & 1996.6-2006.1 & 3.2 & 9.5 & & & & \\
\hline
\end{tabular}

pendix. They consist of time-series of station positions estimated from the VLBI, SLR, DORIS and GPS observations, each expressed in a homogeneous terrestrial reference frame. In the perspective of this study, what we call here a 'pre-processing' step is in fact a set of large and complex geodetic computations that may be summarized as follows. The individual items in time-series of coordinates are originally computed from observations collected over a given time span, 7 days for satellite techniques and 24 hours for VLBI. The data analysis, performed in a free-network approach (Blaha, 1982), derives station specific parameters such as station coordinates, and global ones, such as universal time and pole coordinates. In a second step, the series of loosely constrained sets of station coordinates are referenced to a common external terrestrial reference frame (datum definition). This step involves the adjustment of station motion to a linear model, and the estimation of the seven parameters of a similitude including translation, rotation and scaling of the individual sets of station coordinates (see Altamimi et al., 2006). The signal in the unified series of coordinates will depend on both the modelling in the geodetic analysis and the referencing method. For instance, the satellite techniques, SLR, DORIS and GPS, are sensitive to the motion of the Earth's centre of mass relative to the crust, of which the seasonal variations reach $1 \mathrm{~cm}$ peak to peak. If the time-series of translation parameters are not considered in the unification step, this signal will appear in the station position time-series. Conversely, as the satellite techniques cannot determine the sidereal Earth's orientation, their analysis includes repeated reference to universal time UT1 determined using VLBI. Note that seasonal signatures associated with the data modelling, and not explained yet, also exist in series of translation parameters derived from satellite geodesy data (Feissel-Vernier et al., 2006).

The unification process allows the extraction of the local geodetic signal of interest, leaving out as noise whatever part of the signal does not fit the set of above mentioned models. For classical geodetic applications, those residual time-series are considered as pure noise, except for events like nearby earthquakes or observing equipment changes. Nevertheless, these residuals exist and they can be used to learn something about the type of noise associated with long-term station positioning, in particular noise characteristics of the observing techniques and of the geodetic sites.

In order to allow direct comparison of the results obtained by the various techniques, the analysis focuses on sites where at least two of the techniques are operated (col- location sites). Measurement stability is investigated using the Allan variance criterion in four different analysis schemes, each of which have its strengths and drawbacks, and we compare their results in order to draw general conclusions on the performance of the techniques and the stability of the sites.

The time-series of station positions are first analysed individually in Section 3.2 to estimate the noise level and spectral parameters that characterise their long-term behaviour. A uniform stability ranking is established, for each technique individually, and across techniques. A first global estimate of the observing techniques stability is obtained. This first approach ignores the fact that stability may differ from site to site, independently of the quality of the stations they host. The analyses of Section 4.1 take this fact into account by substracting the site noise contribution in the comparison of collocated observations, and solving for the technique-specific noise level and type, by the threecornered hat method for the 11 sites observed with three or four techniques. This second estimation is rigorous in principle for each site, but the small number of sites suitable for its application restrains the generalization of the conclusions. The three-cornered hat method is then applied in Section 4.2 globally to all collocated stations, providing a third estimate of the technique noise level and type. Finally, instead of being ignored or substracted, the site noise level and type are estimated in parallel with the technique ones in Section 5. The obtained results are discussed in Section 6.

\section{Data}

The sets of collocated time-series available for analysis are described in Table 1, with details of the individual stations and series given in Appendix (Table 7). They include time-series of three-dimensional coordinates spanning between 4 and 16 years, for about 150 stations that are likely to contribute to interconnecting the technique networks in about 60 sites, i.e. areas with stations close enough to be considered belonging to a consistent physical neighbourhood. These are the sites used to interconnect the networks operated with one of the four global geodetic techniques. Intra site distances are generally shorter than $1 \mathrm{~km}$. They are larger than $5 \mathrm{~km}$ in a few cases. The concept of a consistent physical neighbourhood is used here to support the assumption of common noise type that is made in our analysis. For this reason, two sites were split into sub-sites, and three sites were discarded to take into account the local distribution of stations (see Section 4). 


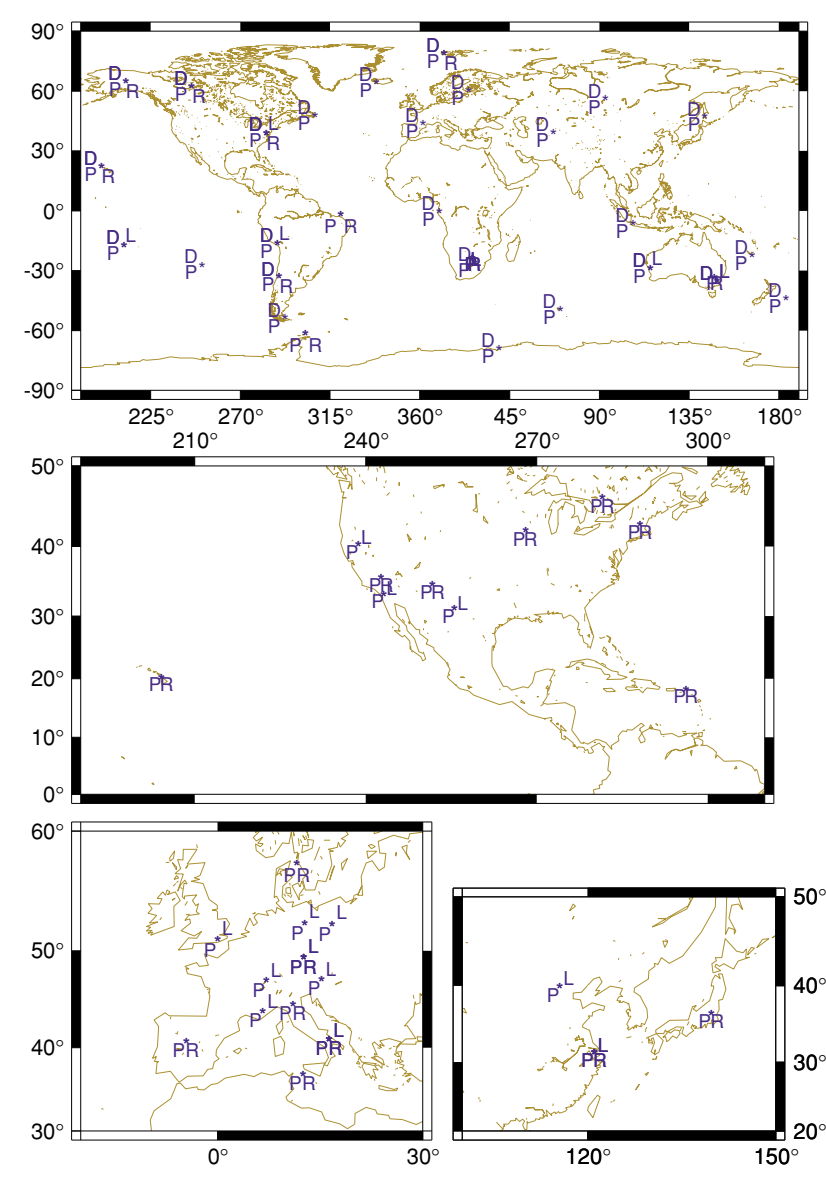

Fig. 1. Collocation network. Top: sites involving DORIS, and 3 VLBI-GPS sites (Brazil, Antarctica, Australia); middle: North America and Eastern Pacific; lower left: Western Europe; lower right: Western Pacific. Techniques: VLBI (R), SLR (L), DORIS (D), GPS(P).

The collocation sites are mapped in Fig. 1 with the 31 sites including DORIS stations plus 3 VLBI-GPS collocation sites in the upper graph, and 24 other sites in North America and Eastern Pacific, Western Europe, and Western Pacific. In these figures and in the rest of this article, the technique names may be abbreviated IERS-wise, using $\mathrm{R}$, L, D, and P for VLBI, SLR, DORIS, and GPS, respectively.

The time-series of station positions used in this study result from multi-parameter data analyses, as briefly outlined in the Introduction. In these complex processes, some parts of the models, parameters and analysis strategies can be expected to impact the derived sets of station coordinates. In this section we examine aspects of the data generation process (the so-called data pedigree) that may play a role in the implementation or in the interpretation of our statistical investigations.

The major steps in the data preparation are described hereafter. They concern the linear and seasonal motion filtering, the consideration of position discontinuities and data gaps, and the compaction of all data into time-series of normal points at common epochs.

\subsection{Data pedigree}

Station motion described by the series of station coordinates is, in principle, influenced by the status of the global parameters that contribute to the definition of the origin, orientation and scale of the underlying terrestrial reference frame, and their time evolution. These parameters concern the terrestrial reference frame itself, as well as the 'terrestrial' Earth Orientation Parameters (EOP): universal time UT1 and polar motion. ITRF2000 plays an important role as background reference frame in the unification of the time-series of coordinates. It is reminded that its origin was defined by SLR TRF results, its scale was defined by VLBI and SLR TRF results, and the time evolution of the orientation was defined by a no-net-rotation condition with respect to a geological plate motion model (Altamimi et al., 2002).

The data used here were provided directly by their authors in the case of VLBI and SLR, or extracted from the international DORIS and GPS services (IDS, IGS) results. They generally follow the IERS Conventions (McCarthy and Petit, 2004), which is expected to prevent large systematic differences in any of the major derived geodetic parameters.

- The VLBI series of station positions were computed by the NASA/GSFC group using the CALC-SOLVE software package; results are available starting in the mid-1980s for most stations. They result from a long-established analysis program and can be considered as representative of the technique's positioning performance. The referencing of the session results to ITRF2000 includes a no-net-translation condition, the use of the corresponding EOP, and no adjustment in scale (Ma, personal communication). Results were used starting in 1990, when the operation of the VLBI network reached a first maturity stage (Gontier et al., 2001).

- The SLR series were computed by the Observatoire de la Côte d'Azur, OCA, (Coulot, 2005), using the GINSDYNAMO software package. Referencing time-series of positions to ITRF2000 is done by applying a sevenparameter no-net-transformation condition to the weekly solutions, based on a subset of reliable stations. Results are available from 1993. These series have been shown to have a stability level close to that of one of the official ILRS series (Coulot, 2005), and are therefore considered representative of the technique.

- The DORIS series were computed by Collecte, Localisation Satellites, CLS, (Soudarin and Crétaux, 2006a, 2006b) using the GINS-DYNAMO software package. Referencing time-series of positions to ITRF2000 is done by applying a seven-parameter no-net-transformation condition to the weekly solutions, based on a subset of reliable stations. Results are available starting in 1993. The DORIS results are known to be of increasing quality with the extension of the satellite constellation (Tavernier et al., 2006). Only two independent sets of station position time-series are currently available. Their noise levels and types are very close to each other (Le Bail, 2006).

At least three satellites are available for global geodetic applications since 1994, and five over 2002-2004. Here, the data were considered starting with 1994.0.

- The GPS series were derived by the AIUB Analysis Centre "CODE" of the IGS using the Bernese software. They were downloaded from the IGS data centre ftp://macs.geod.nrcan.gc.ca/pub/requests/sinex/coord_r/'station'_cod.utm. The referencing of the weekly solutions to ITRF2000 included a no-net-rotation condition and 
no adjustment in scale or origin (Hugentobler, personal communication). The geocentre is known to undergo seasonal variations with $1 \mathrm{~cm}$ peak to peak amplitude. In the case of GPS, the observed motion is complicated by the propagation of modelling errors in the solar pressure effect on the satellite orbits, which also have a seasonal signature (Hugentobler and Beutler, 2005). As a result, the observed seasonal station motion may be partly due to neglected geocentre motion in the referencing of the time-series. Homogeneous results are available since 1996.6. According to our criteria, this set of time-series is one of the the most stable ones among those made available by the IGS. As for the other IGS analysis centres results, they may suffer from analysis changes that take place over the years. The possible consequences in comparison with homogeneously reprocessed series are discussed in Section 3.2 and 6.3.

- Technique-specific combined series are not yet available publicly, except in the case of GPS, with the IGS combined series available at ftp://macs.geod.nrcan.gc.ca/pub/requests/sinex/coord_r/'station'_igs.utm. These time-series are based on weighted means of several analysis centres results (Ferland et al., 2000). They benefit from careful data screening, correction for systematic differences and averaging of random errors. In addition, the series are referenced to ITRF2000 using a seven-parameter transformation (Hugentobler, personal communication). These series were used for complementary tests.

\subsection{Reference frame effects}

When using time-series of collocated station positions, one should be cautious to avoid the following well-known deficiencies.

- The accuracy of local ties is often questioned (Ray and Altamimi, 2005), and the need for their improvement is recognized (see Richter et al., 2005), notwithstanding recent efforts, in particular at key sites like Hartebeesthoek and Shanghai (e.g. Michel et al., 2005).

- The station velocities estimated in the context of the various networks are not necessarily identical for two techniques operated in the same site, even when they are referred to a common terrestrial reference frame, e.g. ITRF2000. This may be the effect of unmodelled errors in the analyses, or may result from uneven and different geometries of the network connected with the background ITRF. Our purpose is to characterise the non-linear interannual behaviour of the time-series as a function of the time scale. Therefore, the time-series of coordinates are first transformed into times series of residuals relative to linear motion. Working on such residual series frees us, by construction, from the two above mentioned issues.

- In addition, the referencing of series of free-network solutions to ITRF2000, or to any other terrestrial reference frame, is implemented on a subset of stations that are judged reliable over the data span. The noise in these particular station time-series propagates into the translation, rotation and scale parameters that are estimated in the datum definition process, creating in the effective underlying terrestrial reference frame a jitter that may propagate back into individual time-series. The level of this network noise is difficult to assess. It may be expected to be lower for the dense DORIS and GPS networks than for the sparse VLBI and SLR ones. In the two latter cases (sparse networks), as long as the network geometry remains stable, the loss of degrees of freedom associated with the frame alignment only affects the linear part of the signal, and not the residuals studied here.

One may be concerned with the various approaches taken to align the individual frames to ITRF2000. One of the intents of this paper is to refer to results actually available. The choice of alignment constraints is part of the responsibility or their authors, with the possible exception of the CODE GPS series, where they result from internal IGS conventions (Hugentobler, personal communication).

\subsection{Seasonal variations}

For all techniques, a number of time-series have annual signatures with millimetric amplitudes, studied in particular by Titov and Yakovleva (1999), Petrov and Ma (2003), Petrov and Boy (2004), Ding et al. (2005), and Gontier et al. (2006) for VLBI, Mangiarotti et al. (2001), Williams and Willis (2006), and Le Bail (2006) for DORIS, Langbein and Johnson (1997), Blewitt and Lavallée (2000, 2002), Dong et al. (2002), Penna and Stewart (2003), Ding et al. (2005), and Feissel-Vernier and Le Bail (2006) for GPS. In the case of SLR, Nicolas et al. (2006) studied the seasonal variations on vertical positioning at the Grasse station, considering also GPS and absolute gravimetry observations. We verified that, as is the case for the three other techniques, seasonal variations may be present in all three local directions at the SLR stations considered in this study. Collilieux et al. (2007), investigated the consistency of local seasonal signal in height at the VLBI, GPS, and SLR collocation sites. They explain the similar signals by the various techniques by a mix of geophysical effects such as atmospheric and hydrological loading, common modelling defects, e.g. on tropospheric effect in radio electric techniques, and instrumental and environmental effects.

To avoid the contamination of the longer term statistics, the series of residual coordinates are further corrected for seasonal motion. In addition, the DORIS data are known to be affected, at the level of a few millimetres, by cyclic errors with periods of 118 and 59 days (Le Bail, 2006), resulting from the TOPEX/Poseidon orbit configuration. For this reason, these oscillations are estimated by weighted least squares and taken out from the DORIS time-series of coordinates for data up to the end of operation of the TOPEX/Poseidon mission, in November 2004.

In the case of GPS, Penna and Stewart (2003) showed that the one sidereal day repeat orbit of the constellation and the practice of analysing the data in 24-hour sessions result in aliasing mismodelled sub-daily tidal signals into annual and semi-annual spurious station motion, thus requiring no additional correction in the context of this study. Penna and Stewart also point out a strong aliasing into fortnightly periods. As we only consider one data point every 90 days, the aliased signal average out in the computation. This is also the case for the the SLR/LAGEOS aliased signals at 35 and 17.5 days (see Feissel-Vernier et al., 2006).

The substraction of annual and semi-annual components is also necessary to avoid unwanted signatures that could be created by residual seasonal signals (Le Bail, 2004) in the Allan variance analysis described in Section 3.1. 


\subsection{Data editing and normal points}

Natural events, such as nearby earthquakes or equipment changes, may introduce discontinuities in the observed station motion. Careful checking of anomalous breaks in the time-series was performed, using the available information as well as by direct examination. See the Appendix for more details.

Positioning data are typically provided as time-series of geocentric Cartesian coordinates or, equivalently, series of offsets in local directions to the East, North and Up, in a given terrestrial reference frame. GPS and DORIS series are available at one-week intervals. The average time distribution of SLR and VLBI series is comparable but somewhat irregular, due to the weather dependence in the case of SLR, and discontinuous scheduling in the case of VLBI. A compromise uniform 13-week interval (91 days, close to $1 / 4$ year) was chosen to maximize the number of simultaneous data between techniques.

This is of particular importance for Section 4, where time series of position differences in pairs of stations are used. The data points are obtained by independent weighted average of the residuals of the original series relative to a linear trend and "seasonal" terms derived by weighted leastsquare analysis. The so-called "seasonal" terms consist of annual and semi-annual periodic terms, plus the DORISspecific 118- and 59-day periodic terms mentioned in Section 2.3. The series at 91-day intervals have practically no gaps, except for a few VLBI stations with sparse observations. In the data analyses that require a continuous timeseries, the few gaps left $(5.8 \%)$ are filled by random values with a noise level consistent with that of the surrounding points. In the individual series, the $8.2 \%$ outliers exceeding $2.5 \sigma$ were brought back to that level in order to avoid the appearance of artificial flicker noise signatures.

\section{Station Position Stability}

\subsection{Allan stability parameters}

The stability evaluation aims at characterising the level and spectral type of what is commonly considered as nuisance signal in the geodetic and geophysical uses of spacegeodetic positioning. In other words, in our study, noise becomes the signal to be investigated.

The stability of station positions is expressed in terms of the Allan variance (Allan, 1966, 1987; http://www.allanstime.com/AllanVariance/). The Allan variance of a time series $X_{i}$ with $\mathrm{N}$ items and sampling time $\tau$ is defined by:

$$
\sigma_{A}^{2}(X, \tau)=\frac{1}{2 N} \sum_{i}\left(X_{i+1}-X_{i}\right)^{2} .
$$

The Allan variance of position residuals, for a given time interval, is computed by averaging position the residuals over that interval and computing the variance of differences between adjacent averaged values.

The Allan variance analysis was developed and is widely used for estimating the frequency stability of atomic clocks. We extend here this tool, and the statistical theory developed around it, to geodetic data. It allows one to characterise the type of noise and, in particular, to identify white noise (spectral density $\mathrm{S}$ independent of frequency f), flicker noise (S proportional to $\mathrm{f}^{-1}$ ), and random walk noise ( $\mathrm{S}$ proportional to $\mathrm{f}^{-2}$ ). One can simulate flicker noise in an originally white noise time-series by introducing steps of random size at random times. In the case of a white noise spectrum, extending the time span of observations eventually leads to the stabilisation of the solution. Conversely, in the case of flicker noise, it does not improve the quality of the estimated parameters.

The dependence of the Allan variance of a time-series on the sampling time $\tau$ can be interpreted in terms of its error spectrum by means of the Allan diagram, which gives Allan variances for increasing values of $\tau$ (Allan and Barnes, 1981; Percival, 2003). In logarithmic scales, slopes $-1,0$ and +1 correspond to white noise, flicker noise and random walk noise, respectively.

A definition of the stability of station positions is proposed. It accounts for the following specific aspects of the measurement of station motion: the three-dimensional linear motion (with known discontinuities taken care of), the possible presence of a mix of seasonal motions and seasonal analysis errors, and the existence of a residual signal. This definition includes two stability parameters in each reference direction of the local frame (East, North, Up), namely:

- the noise level measured by the Allan deviation for a one-year sampling time of the non-linear, nonseasonal position time-series,

- the noise type measured by the slope of the Allan graph, which describes the log-log relationship of the Allan variance of a time-series with the corresponding sampling time.

In the context of this study, a white noise signature in the position residuals would comfort the basic linear motion model, while a flicker noise signature would point to perturbations that limit the relevance of this model. These perturbations may have different origins, like local tectonics, instrument defects, analysis consistency, etc. Note that, according to Williams (2003), uncorrected jumps in a timeseries will cause the series to evolve as random walk. In our data preprocessing, such signal would be transformed into flicker noise by the linear motion correction. More generally, as the Allan graph slope of a time-linear variation is +2 , close to that of random walk signature, the latter is not likely to be found in series of station position residuals. No random walk noise diagnostic were actually found in our analysis.

Examples of time-series of residuals with the corresponding Allan variance graphs are shown in Appendix A.3 for one station for each technique.

\subsection{Stability of station positions}

The time-series of station positions were submitted to Allan variance analysis in order to determine directly the three pairs of stability parameters. The results are plotted in Fig. 2. The noise level in the East, North and Up directions is shown, in millimetres, for the stations in each site, with the various techniques appearing in the same following top-to-bottom order and with a specific colour: VLBI (red), SLR (light blue), DORIS (pink), and GPS (blue). The sites are sorted by latitude. The noise type, inferred from the slope of the Allan graph, is symbolized at the end of the 


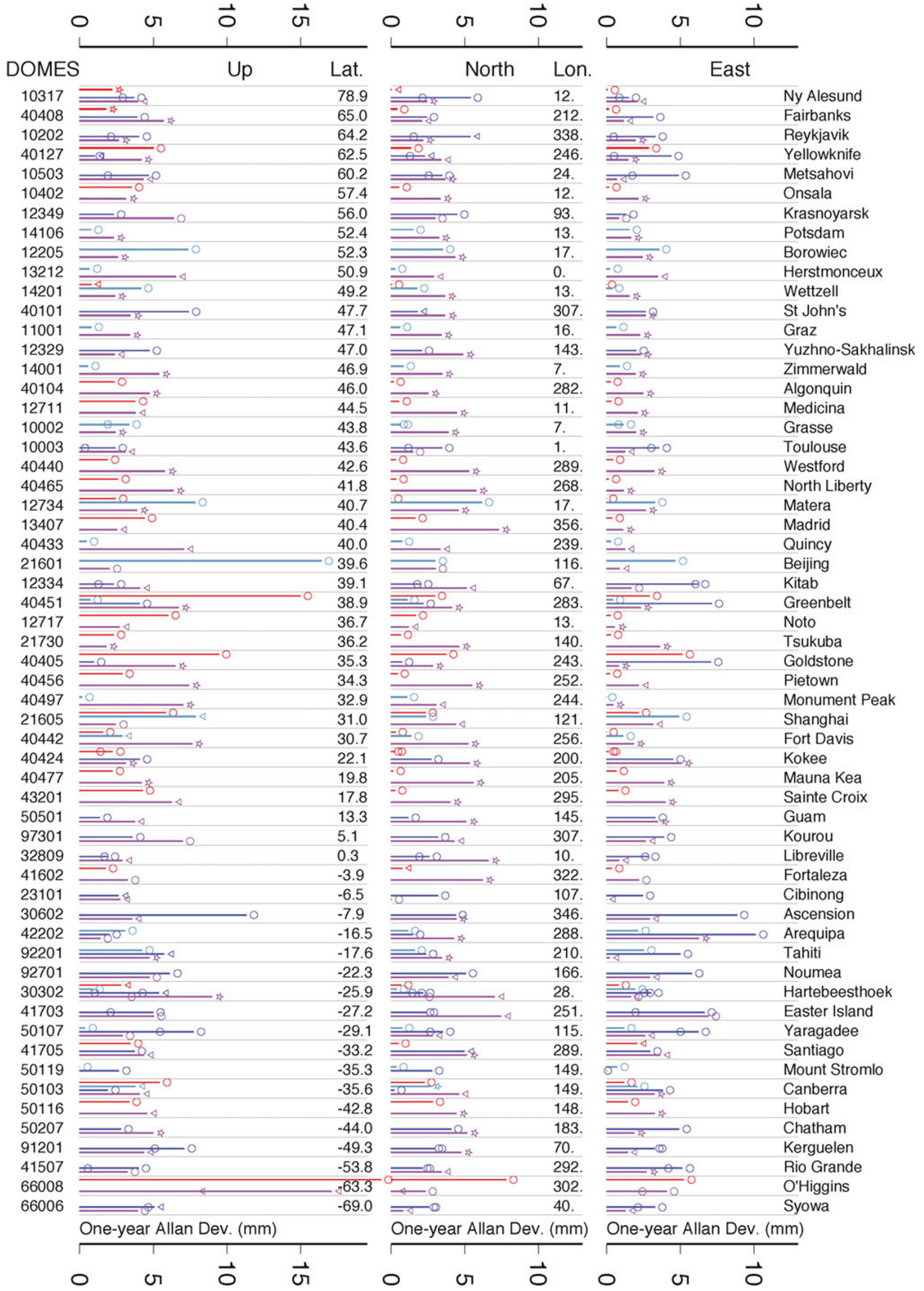

Fig. 2. Station stability: noise level and noise type. VLBI (red), SLR (turquoise), DORIS (blue), GPS (purple); white noise (o), flicker noise (*), indecisive noise $(\nabla)$. The DOMES number, latitude, longitude and name of the sites are given. The sites are sorted by latitude. 


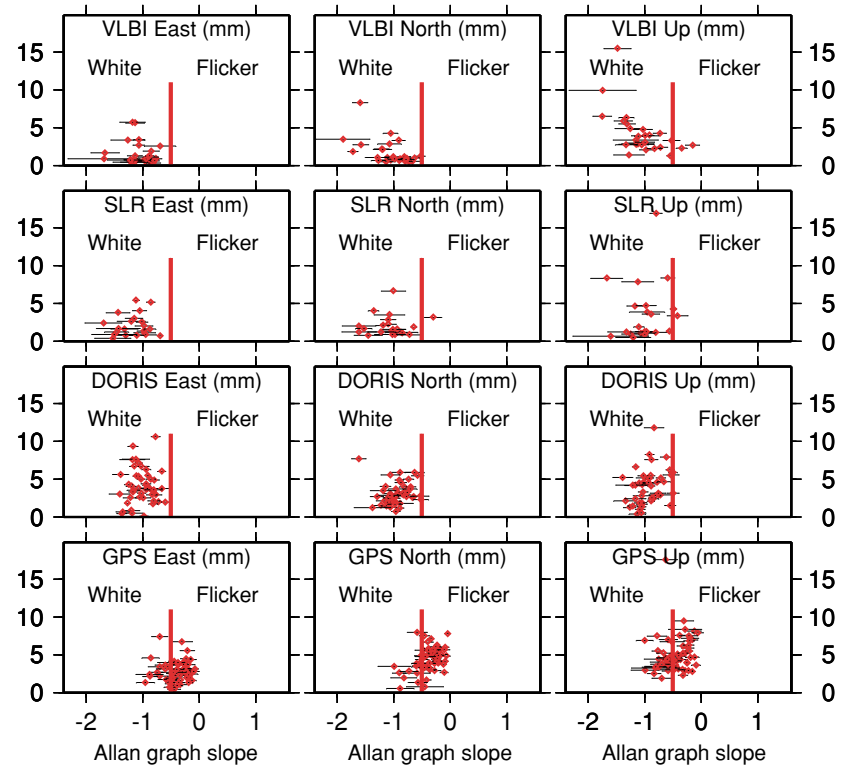

Fig. 3. Distribution of noise type (abscissas) and noise level (ordinates) for the VLBI, SLR, DORIS, and GPS stations of Fig. 2.

Allan deviation bar, by a circle for white noise, or a star for flicker noise. In the cases where the $1-\sigma$ error bar of the Allan graph slope crosses the -0.5 virtual limit between the white and flicker noise zones, we took the conservative option to consider the noise type as indecisive. These situations are symbolized by inverted triangles $(\nabla)$. Williams et al. (2004) find that the noise level of the GPS stations is generally larger in the Southern hemisphere, maybe due to a sparser network in that area. Our stability analysis does not show clearly such effect.

A synthetic view of the station stability evaluations is given in Fig. 3, where the noise level is plotted as a function of the Allan graph slope, equivalent to the noise type, in each of the three local directions and for each of the techniques. The following general comments may be made.

- The plots are composed of rather compact clusters with few outliers, and they have different characteristics depending on technique and direction, suggesting that the pairs of stability parameters defined in Section 3.2 are relevant for describing the quality of station motion measurements.

- White noise dominates in all directions for VLBI, SLR and DORIS. The result concerning DORIS agrees with those obtained for the one-week sampling time by Le Bail (2006), who used similar noise type detection methods. They only partly agree with Williams and Willis (2006). The latter, using a Maximum Likelihood Estimation criterion to estimate the relative contribution in a linear combination of modelled noises, conclude that the DORIS positioning data exhibit a balanced-level mix of white and flicker noises.

- GPS results show a balanced mix of white noise and flicker noise, in the East and Up directions. Flicker noise is more frequent in the North direction, with higher noise levels than in the East direction. This may be connected with the analysis centre considered, as these peculiarities are not present in the case of the IGS combined solution (Feissel-
Vernier and Le Bail, 2006). These results are consistent with earlier estimations, e.g. Langbein and Johnson (1997), Zhang et al. (1997), Mao et al. (1999), Williams et al. (2004). Note the larger proportion of indecisive noise type results, symbolized by inverted triangles in Fig. 2, which may be compared with the presence of a mix of white noise and flicker noise detected by Williams et al. (2004).

- For horizontal positioning, VLBI stations are the most stable ones $(1 \mathrm{~mm})$, except for the sparsely observed O'Higgins station. The SLR noise level is close (2 mm), with a few poorer quality stations (Borowiec, Matera, Beijing, Shanghai, see Appendix A.3. DORIS stations are less stable in the East-West direction than in the North-South one (4 $\mathrm{mm}$ and $3 \mathrm{~mm}$ respectively). According to Williams and Willis (2006), this results from the dominance of NorthSouth and South-North satellite passes over the stations. GPS positioning is more stable in the East-West direction than in the North-South one ( $3 \mathrm{~mm}$ and $4 \mathrm{~mm}$ respectively). The poorer quality in the North-South direction is not confirmed by our analysis of the IGS solution, where the median noise levels in both horizontal directions are very close to each other. This seems to be related to specific problems in the CODE solution.

- For vertical positioning, SLR is as stable as in the horizontal directions: $1-2 \mathrm{~mm}$ for the best group. Among the radio electric techniques, known to be limited by the modelling of the troposphere propagation delay, VLBI stations have the lowest noise level $(3 \mathrm{~mm})$, although the degradation relative to horizontal stability is the largest among the four techniques. The DORIS and GPS measurements, which may suffer in addition from inaccurate antenna phase centre corrections, reach the same $4 \mathrm{~mm}$ level.

Some anomalously large noise levels in a few stations may be commented as follows.

- The VLBI station 7108 at Greenbelt (40451) has a large noise level in the Up direction. It is a small antenna station, used for the mobile campaigns in North America and Europe. The observation rate, as seen through 91-d averages, was dense until 1995. After a two-year interruption, the observations started again at a lower rate, and with a higher noise level in the Up direction.

- The time-series of the SLR station at Beijing is sparse and noisy, which could explain its poor stability, in particular in the Up direction.

- The DORIS time-series at Arequipa and Ascension are particularly noisy in the East direction, which might be associated with signal loss at the station due to tracking conflicts.

- The GPS station HERS at Herstmonceux (13212) has a strong anomaly in the Up direction, which may be related with the 'antenna problem' for the period 1999.3-2001.6 mentioned by the IGS. Despite this known defect, the data were kept. Thanks to the station weighting used in Section 5, this anomalous behaviour should not affect the estimation of the technique noise level and type, but it may affect the qualification of the site performance. A similar comment may be made for the WES2 station at Westford, which experienced monument instability over 2001.62002.6. The OHIG station at O'Higgins with high noise level in the Up direction is sparsely observed. 
Table 2. GPS: noise level and occurrence of white noise stations according to the analysis circumstances.

\begin{tabular}{l|ccc|ccc}
\hline Solution & \multicolumn{3}{|c}{ White noise stations } & \multicolumn{3}{c}{ 1-yr Allan Deviation } \\
& $E$ & $N$ & $U$ & $E$ & $N$ & $U$ \\
\hline \multirow{8}{*}{ CODE } & $22 \%$ & $25 \%$ & $39 \%$ & 1.7 & 2.6 & 2.7 \\
IGS & $30 \%$ & $22 \%$ & $30 \%$ & 1.0 & 1.3 & 2.5 \\
& \multicolumn{8}{|c}{ Operational } \\
ULR & $84 \%$ & $78 \%$ & $86 \%$ & 0.7 & 0.6 & 1.5 \\
\hline
\end{tabular}

The noise level and type estimations are performed under a stationarity assumption, in other words we consider that the scattering of the data is homogeneous in time. This is indeed only approximately true in real time-series. The scatter of SLR and GPS series may be considered as homogeneous starting with 1993 and 1996, respectively. The VLBI series were considered starting with 1990. In the DORIS case, the noise level is an average of that allowed by the numbers of satellites available during the observation periods.

The present evaluation of the spectral behaviour for the four space-geodetic techniques on the basis of station data is restricted to the analysis of the motion of collocated stations. Can one consider the collocated sub networks as representative samples of their respective techniques in this respect? This question is discussed in Appendix, using the station stability index proposed by Le Bail et al. (2006). We conclude that, as far as the stability of station motion measurement is concerned, the set of collocated stations represents an acceptable proxy for the complete network.

For reaching conclusions on the technique-specific noise level from the analysis of individual stations, one may consider that it is smaller than any station noise level for this technique. However, this is true only in a statistical sense. We decided to select the median for the group of the best observed stations as a proxy for the technique noise level and type.

The results are summarized in Section 6, together with those obtained by the alternative methods described in Sections 4 and 5. Lines with heading 'Stations' in Table 5 give the median noise levels and weighted median Allan graph slopes for the well observed stations (no data gap longer than 200 days) within each technique. The median noise levels are also plotted in Fig. 6 (stars).

\subsection{The case of reanalysed solutions}

Among the four techniques considered, GPS is the only one for which white noise is not dominant. While the VLBI, SLR, and DORIS series each result from a unique global analysis, the GPS series (CODE and IGS) are constructed in an operational mode, with generally no re-analysis of the past data when improvements are brought in the analysis procedures. This analysis process is likely to produce random steps at random dates, which is known to produce flicker noise. A few homogeneously analysed series are available, such as the SOPAC solution analysed by Williams et al. (2004), or that derived by Steigenberger et al. (2003), for which the time series of station positions are unfortu- nately not yet available (Steigenberger, personal communication). Another solution, derived by Wöppelmann et al. (2007) using the MIT GAMIT software, referred to as ULR, was made available to us while this paper was in the final revision stage. It includes about 150 time-series that match our selection criteria (see Section 3.2). They cover the years 1999 through 2005. We use it here to check the influence of the analysis process. Submitting them to the analysis process described in Appendix A.1, we evaluate the proportion of stations exhibiting white noise in the East, North, and Up directions, and we compare those to the performance of the CODE and IGS solutions in Table 2. While the rate of white noise stations stays in the range $20-40 \%$ for both operational solutions, it is in the range 78-86\% for the reanalysed solution, confirming partially the abovementioned origin for flicker noise. The cause for the remaining 15-20\% flicker noise spectra would deserve further investigation. Table 2 also gives the noise levels in terms of the median Allan deviation for the one-year sampling time in the East, North, and Up directions. The improvement for the reanalysed solution ULR over the operational solutions is impressive, as the single-centre reanalysed solution values are about half of those of the combined operational IGS solution. Referring to lines with heading 'Stations' in Table 5, we see that the ULR series match the VLBI level in horizontal, and the SLR level in vertical.

\subsection{Comparison with station stability evaluation based on post fit residuals of TRF combination}

Our noise level evaluations may tentatively be compared with the noise levels found by Altamimi et al. (2005), despite different statistical approaches. The Altamimi et al. evaluations are based on the combination of time-series of station positions derived from the four techniques. The solutions are single-centre ones, except in the case of GPS, for which the IGS combined series, close to that mentioned in Section 2.1, were used. The VLBI analysis centre is the same as in this study, while the SLR and DORIS analysis centres are different. As far as the two different DORIS analyses are concerned, Le Bail (2006) showed that their noise levels and types are very close to each other. The estimations result from the CATREF combination (Altamimi et al., 2001; Altamimi and Collilieux, 2007), which includes the consideration of local geodetic ties and the combination of the EOP series. The estimated station parameters are a $3 \mathrm{D}$ position at a reference epoch and a unique 3D linear velocity per site. The sampling interval is one week, not one year. The derived noise levels are labelled as horizontal 2D and Up.

The process producing the a posteriori residuals includes a number of additional parameters, assumptions and constraints, whereas that used in this study implies only the assumption of linear 3D velocity for each station individually. We nevertheless propose in Table 3 a comparison of these estimates. The columns labelled Altamimi et al. (2005) reproduce the values of Table 2 in that paper. The columns labelled 'This study' list the median of the Allan deviation for the well observed stations of each technique, computed for two sampling times: seven days to stay close to the Altamimi et al. analysis conditions, and one year, the standard sampling time considered in this paper. 
Table 3. Technique noise levels according to Altamimi et al. (2005), and in this study, calculated for the seven-day and the one-year sampling times.

\begin{tabular}{l|rr|rr|rr}
\hline \multicolumn{1}{c|}{$\begin{array}{c}\text { Technique } \\
\text { Solution }\end{array}$} & \multicolumn{2}{|c|}{ Altamimi } & \multicolumn{3}{c}{ This study: sampling times } \\
& et al. $(2005)$ & \multicolumn{2}{c}{ Seven-day } & \multicolumn{2}{c}{ One-year } \\
& $2 D$ & $U p$ & $2 D$ & $U p$ & $2 D$ & $U p$ \\
\hline VLBI & 2 & 3 & 6 & 11 & 1.1 & 2.8 \\
SLR & 3 & 5 & 12 & 9 & 2.1 & 1.3 \\
DORIS & 10 & 12 & 27 & 16 & 4.8 & 4.2 \\
GPS/CODE & - & - & 8 & 8 & 4.9 & 4.4 \\
GPS/IGS & 2 & 5 & 3 & 4 & 1.6 & 2.5 \\
\hline
\end{tabular}

Considering the seven-day sampling time, the two types of evaluations are roughly consistent for the combined IGS solution in both the horizontal and vertical planes, and for SLR and DORIS in vertical. Our noise estimates are 43 times larger for VLBI, SLR, and DORIS in horizontal, and for VLBI in vertical, than the Altamimi et al. ones. Note that the noise level for the single GPS analysis centre, CODE, is at a level comparable with that of the corresponding VLBI and SLR solutions.

When going from one week to one year, the ranking between VLBI, SLR and DORIS, all exhibiting white noise, remains the same, with again a high value for VLBI in height. Due to the flicker noise spectrum of both GPS solutions, the ranking of GPS with respect to the three other techniques is much changed: the VLBI and SLR single analysis centre noise levels are at the level of the IGS combined solution, and the single analysis centre GPS noise level is close to that of the corresponding DORIS solution. Considering these large differences between short-term and long-term statistical behaviours, we propose in Section 6.1 an alternative weighting scheme for the combination of terrestrial reference frames.

\section{Estimating the Technique Noise with the Three- Cornered Hat Algorithm}

The results of Section 3.2 help to define the stability of stations individually. Although the performance of the stations is scattered within each technique, they give a first idea of the technique noise characteristics. In this section, we test a more direct way to estimate technique-specific stability by applying the three-cornered hat method. This method allows the estimation of the noise variance of three or more independent sets of measurements of the same quantities, here the three-dimensional residual motion.

After studying the collocation sites local geometry (see details in the Appendix), we decided that stations located within $1 \mathrm{~km}$ from each other could in general be considered belonging to the same physical site. Three sites (Ascension, Guam, and Kourou) cannot be considered because of too large intra-site distances combined with varying local geology. Four sites with inter-station distances in the range 1$3 \mathrm{~km}$ (Reykjavik, Ny Alesund, Metsahovi, and Fairbanks) are kept for the study. Two sites (Hartebeesthoek and Orroral) are split into two sub-sites each, resulting in a total of 56 physically meaningful collocation sites observed by 144 stations. The three-cornered hat method is applied first to every site where at least three of the techniques are oper- ated (Section 4.1), and then globally to the complete set of collocation sites (Section 4.2).

\subsection{Technique noise level determined at individual} sites

The three-cornered hat algorithm allows, when three independent time-series of measurements of the same quantity are available, to get an estimation of the Allan variance of each of them. It is based on the hypothesis that the common part of the three measurements is the true signal, and that the non common part, assumed to be pure noise, is totally uncorrelated. For each of the time-series $X_{k}(t), k=1,2,3$, we have

$$
X_{k}(t)=X(t)+\epsilon_{k}(t)
$$

where $X(t)$ is the true signal, and $\epsilon_{k}(t)$ the noise of measurement $k$. After the difference between two times series is computed, only the difference between the two noises remains. As they are uncorrelated by hypothesis, their Allan variances for sampling time $\tau$ verify the relationship

$$
\sigma_{A}^{2}\left(X_{k}-X_{j}, \tau\right)=\sigma_{A}^{2}\left(\epsilon_{k}, \tau\right)+\sigma_{A}^{2}\left(\epsilon_{j}, \tau\right)
$$

With three series, we can make three such equations, which can then be solved for the individual noise variances. If more than three measurements are available, we can make more differences, and the problem can be solved by a least square fit. This was first shown by Gray and Allan (1974). More recently, the three-cornered-hat technique was generalized in the frame of time and frequency metrology under the hypothesis that the noise of the different series are correlated, but that this correlation is very weak (e.g. Premoli and Tavella, 1993). This extended concept was successfully applied by Koot et al. (2006) in the geodetic domain for the validation of time-series of atmospheric angular momentum. We used the algorithm developed in the latter work.

The subset of 11 sites observed by three techniques that can be used for applying the three-cornered-hat technique are Ny Alesund, Matera, Wettzell, Shanghai, Hartebeesthoek $a$, Yellowknife, Fairbanks, Kokee, Arequipa, Yaragadee, and Tahiti. The only site observed by the four techniques that can be used is Greenbelt. The common observation spans are listed in the Appendix (Table 10). The numbers of time-series differences involving the techniques are 19 in 9 sites for VLBI, 17 in 8 sites for both SLR and DORIS, and 25 in 12 sites for GPS.

The results are summarized in Section 6, together with those obtained by the alternative methods described in Sections 3.2, 4.2 and 5. The length of most parallel data spans lies within the range 7-11 years. This was in general too short to estimate the Allan variance for the four-year sampling time. The missing end-value of the plot prevents reliable evaluation of the long-term behaviour of the series by means of the slope of the Allan graph. Lines of Table 5 with heading 'TCH/site' give the median of the noise levels derived from the 39 series of coordinate differences in each of the East, North, and Up directions in the 11 sites studied in this section.

The Allan variances for sampling times 91 days through 2 years are plotted on Fig. 6 (symbol: $\Delta$ ). 


\subsection{Technique noise level and type determined globally}

Instead of solving sets of equations (Eq. (3)) site by site, we now make the assumption that we can use the variance of the difference between two collocated time-series of positions as a measurement of the difference of technique noise, even if we only have two techniques operated in that site. We build a global system based on Eq. (3), considering all pairs of parallel time-series. Solving it by a least square fit, we obtain an estimation based on the complete collocation network.

The results are summarized in Section 6, together with those obtained by the alternative methods described in Sections 3.2, 4.1 and 5. Lines of Table 5 with heading ' $\mathrm{TCH}$ global' give the noise levels and Allan graph slopes derived from the 144 stations in 56 sites studied in this section.

The Allan variances for sampling times 0.25 through 4 years are plotted on Fig. 6 (symbol: $\nabla$ ). Missing values, in particular for VLBI in the East direction, indicate that the estimated variance was found to be negative. The results are in some cases not well aligned. One cause may be that the difference of time-series that is performed to start with contains very little common signal.

\section{Estimating Site and Technique Noise by a Least Square Fit}

The application of the three-cornered hat technique is based on the assumption that there is a common signal in the series of measurement residuals that are going to be differenced. In the present case, the correlation between parallel series of residuals is, in fact, generally weak, and we could expect that the three-cornered hat approach may not fully appropriate to the real data. In this section we apply another modelling, based on the assumption of uncorrelated residual position signals.

We assume that the Allan variance of the station's signal is composed of two parts,

- a variance associated with the observing technique, and

- a variance characterising the site itself, either because it undergoes deformations of geophysical origin, or because of other causes such as pillar instability or atmospheric anomalies.

Using a simple additive variance model, we analyse the collocated station position time-series to derive these two sets of Allan variances, as a function of the sampling time. We thus obtain estimations of the noise level and type parameters defined in Section 3.2 to describe separately the performance of the measuring techniques and that of the sites.

Regarding the contribution of the site and technique variances to the observed one, our additive model is based on the following assumptions.

- The noise level and type associated with the site is common to all the stations in the same site, regardless of the observation epochs. As a result, it may reflect not only real local conditions, but also modelling deficiencies that are common to the collocated techniques.

- The contribution of the technique noise level takes into account the fact that stations of the same technique may have different stabilities (see Fig. 3). It is weighted by the ratio between the individual station's one-year Allan variance (see Fig. 2) and the median one-year Allan variance for the technique (lines labelled 'Stations' in Table 5).

The analysis is based on normal equations written as

$\sigma_{A}^{2}($ station, $\tau)=\sigma_{\mathrm{A}}^{2}($ site,$\tau)+\alpha \cdot \sigma_{\mathrm{A}}^{2}($ technique, $\tau)$,

where $\sigma_{A}^{2}(., \tau)$ is the Allan variance for sampling time $\tau$, and $\alpha$ is the above-defined ratio. We can then solve the equation system based on normal equations(Eq. (4)), and obtain the Allan variance of the noise associated with each site and each technique.

The parameters were fitted on the set of 56 collocation sites with expected common behaviour, according to criteria described in the Appendix. The rms post-fit residuals for the one-year sampling time are $(2.6 \mathrm{~mm})^{2}$ in the East direction, $(2.2 \mathrm{~mm})^{2}$ in North, and $(3.0 \mathrm{~mm})^{2}$ in Up, with only a couple of outliers at the $2.5 \sigma$ level.

The stability results per site are described in Section 5.1, and those per technique are described in Section 5.2.

\subsection{Site noise level and type}

The estimated site noise levels are given in Table 4 in terms of the Allan deviation for the one-year sampling time, with uncertainties equal to the square-root of the uncertainty of the estimated Allan variance. The least-square estimation is based on normal equations (Eq. (4)) with variances as unknown parameters. In some cases, negative values of the estimated variance may be found, indicating model failure to explain the noise level for this site and this sampling time. The corresponding results are missing in Table 4. The percentages of occurrence of such cases are $16 \%, 5 \%$, and $4 \%$, in the East, North, and Up directions, respectively. In a couple of cases, the Allan deviation for the one-year sampling time could be inferred from the estimates for the other sampling times.

The relatively high failure rate in the East direction may be related to less clustered noise levels of the four techniques, as it happens to be the noisiest direction for DORIS, and the least noisy for VLBI. DORIS positioning is known to be noisier in this direction because of the orbit configuration (Le Bail, 2006; Williams and Willis, 2006). VLBI noise level is higher in the North than in the East, which may be related with the poor tropospheric modelling for low elevation observations, which in turn are more numerous in the North-South direction due to lack of long baseline components in the observing network. The influence of this defect on radio source declinations is well documented (Ma et al., 1998; Gontier et al., 2001). This effect is minimized but not completely cancelled by the application of an atmospheric gradient correction (McMillan and Ma, 1997). It brings the VLBI noise level closer to that of the other techniques in the North direction.

The site noise type is also listed in Table 4 whenever its evaluation was judged to be reliable, i.e. when the Allan variance was available for at least three sampling times, including the four-year sampling time.

The site stability evaluations for each of the three local directions are illustrated in Fig. 4. The noise level is plotted in the upper part as a function of the Allan graph slope, equivalent to the noise type. The error bars are 1- $\sigma$. The middle part shows the histograms of the noise level, and the bottom graph shows the distribution of the Allan graph slopes listed in Table 4. The noise level is mostly in the 
Table 4. Site noise level. The table gives the one-year Allan deviation in the East, North, and Up local directions derived with the model of Eq. (4). In the cases when the Allan deviation could not be estimated directly (see text), it is replaced by the value modelled by a linear regression over the other sampling times. Those values are starred (*). The noise type, White noise (Wh) or Flicker noise (Fl), is listed when available (see text).

\begin{tabular}{|c|c|c|c|c|c|c|c|c|}
\hline \multirow{3}{*}{$\begin{array}{l}\text { DOMES } \\
\text { Number } \\
10002\end{array}$} & \multirow{3}{*}{$\begin{array}{r}\text { Site } \\
\text { name }\end{array}$} & \multirow{3}{*}{$\begin{array}{l}\text { Techn. } \\
\text {.L.P }\end{array}$} & \multicolumn{6}{|c|}{ One-year Allan deviation $(\mathrm{mm})$ and noise type } \\
\hline & & & \multicolumn{2}{|c|}{ East } & \multicolumn{2}{|c|}{ North } & \multicolumn{2}{|c|}{$U p$} \\
\hline & & & $0.9 \pm 1.5$ & Wh & $1.7 \pm 1.3$ & Wh & $2.2 \pm 1.7$ & $\mathrm{Wh}$ \\
\hline 10003 & Toulouse & ..DP & - & - & $1.6 \pm 1.3$ & $\mathrm{Fl}$ & $2.9 \pm 1.7$ & $\mathrm{Fl}$ \\
\hline 10202 & Reykjavik &.. $\mathrm{DP}$ & $1.9 \pm 1.5$ & - & $3.4 \pm 1.3$ & - & $2.1 \pm 1.8$ & - \\
\hline 10317 & Ny Alesund & R.DP & $1.3 \pm 1.3$ & Wh & $0.6^{*}$ & Wh & $2.6 \pm 1.5$ & Wh \\
\hline 10402 & Onsala & R..P & $1.2 \pm 1.8$ & Wh & $1.9 \pm 1.6$ & $\mathrm{Fl}$ & $1.9 \pm 2.1$ & $\mathrm{Wh}$ \\
\hline 10503 & Metsahovi &.. $\mathrm{DP}$ & - & - & $2.8 \pm 1.3$ & - & $2.7 \pm 1.8$ & - \\
\hline 11001 & Graz & .L.P & $1.4 \pm 1.8$ & $\mathrm{Fl}$ & $1.8 \pm 1.6$ & $\mathrm{Fl}$ & $2.0 \pm 2.1$ & - \\
\hline 12205 & Borowiec & .L.P & $2.8 \pm 1.9$ & - & $3.1 \pm 1.6$ & Wh & $2.8 \pm 2.2$ & - \\
\hline 12329 & Yuzhno-Sakhalins &.. $\mathrm{DP}$ & $2.6 \pm 1.8$ & - & $1.9 \pm 1.6$ & - & $1.3 \pm 2.2$ & - \\
\hline 12334 & Kitab &.. $\mathrm{DP}$ & $3.1 \pm 1.6$ & - & $1.4 \pm 1.3$ & $\mathrm{Fl}$ & $3.2 \pm 1.7$ & Wh \\
\hline 12349 & Krasnoyarsk &.. $\mathrm{DP}$ & $1.7 \pm 1.8$ & - & $2.4 \pm 1.6$ & - & $1.5 \pm 2.2$ & - \\
\hline 12711 & Medicina & R..P & $1.4 \pm 1.8$ & $\mathrm{Fl}$ & $2.0 \pm 1.6$ & $\mathrm{Fl}$ & $2.9 \pm 2.1$ & Wh \\
\hline 12717 & Noto & R..P & $1.1 \pm 1.8$ & Wh & $1.5 \pm 1.6$ & Wh & $2.3 \pm 2.1$ & $\mathrm{Wh}$ \\
\hline 12734 & Matera & RL.P & - & - & $1.3 \pm 1.5$ & - & $3.3 \pm 1.8$ & - \\
\hline 13212 & Herstmonceux & .L.P & $3.1 \pm 1.8$ & $\mathrm{Fl}$ & $2.6 \pm 1.6$ & Wh & $0.7 \pm 2.2$ & - \\
\hline 13407 & Madrid & R..P & $1.4 \pm 1.8$ & Wh & - & - & $3.0 \pm 2.1$ & - \\
\hline 14001 & Zimmerwald & .L.P & $0.8 \pm 2.6$ & $\mathrm{Fl}$ & $1.7 \pm 2.2$ & $\mathrm{Fl}$ & $3.0 \pm 3.0$ & - \\
\hline 14106 & Potsdam & .L.P & $0.2 *$ & - & $1.6 \pm 1.6$ & $\mathrm{Fl}$ & $2.3 \pm 2.1$ & $\mathrm{Wh}$ \\
\hline 14201 & Wettzell & RL.P & $1.2 \pm 1.5$ & Wh & $1.0 \pm 1.3$ & $\mathrm{Fl}$ & $2.0 \pm 1.7$ & $\mathrm{Wh}$ \\
\hline 21601 & Beijing & .L.P & $5.0 \pm 2.1$ & - & $3.4 \pm 1.6$ & - & $1.1 \pm 2.9$ & - \\
\hline 21605 & Shanghai & RL.P & - & - & $3.0 \pm 1.3$ & Wh & $3.7 \pm 1.8$ & $\mathrm{Wh}$ \\
\hline 21730 & Tsukuba & R..P & $1.4 \pm 1.8$ & $\mathrm{Fl}$ & $1.4 \pm 1.6$ & $\mathrm{Fl}$ & $1.7 \pm 2.1$ & Wh \\
\hline 23101 & Cibinong &.. $\mathrm{DP}$ & $1.3 \pm 1.8$ & - & $0.6 \pm 1.6$ & - & $1.2 \pm 2.1$ & - \\
\hline \multirow[t]{2}{*}{30302} & Hartebeesthoek $a$ & RL.P & $0.9 \pm 1.5$ & $\mathrm{Fl}$ & $1.3 \pm 1.3$ & $\mathrm{Wh}$ & $3.5 \pm 1.8$ & - \\
\hline & $b$ &.. $\mathrm{DP}$ & $1.5 \pm 1.3$ & - & $2.0 \pm 1.1$ & - & $2.2 \pm 1.5$ & - \\
\hline 32809 & Libreville &.. $\mathrm{DP}$ & $2.6 \pm 1.5$ & - & $0.9 \pm 1.3$ & - & $4.2 \pm 1.7$ & - \\
\hline 40101 & St John's &.. $\mathrm{DP}$ & $2.8 \pm 1.8$ & Wh & $2.0 \pm 1.6$ & Wh & $3.3 \pm 2.3$ & $\mathrm{Fl}$ \\
\hline 40104 & Algonquin & R..P & $1.7 \pm 1.8$ & - & $1.3 \pm 1.6$ & Wh & $2.7 \pm 2.1$ & $\mathrm{Fl}$ \\
\hline 40127 & Yellowknife & R.DP & $1.6 \pm 1.3$ & - & $1.0 \pm 1.1$ & - & $2.6 \pm 1.5$ & $\mathrm{Fl}$ \\
\hline 40405 & Goldstone & R..P & - & - & $2.0 \pm 1.6$ & $\mathrm{Fl}$ & $3.0 \pm 2.2$ & $\mathrm{Fl}$ \\
\hline 40408 & Fairbanks & R.DP & $0.6 \pm 1.5$ & - & $1.6 \pm 1.3$ & Wh & $4.0 \pm 1.8$ & $\mathrm{Fl}$ \\
\hline 40424 & Kokee & R.DP & $1.4 \pm 1.3$ & Wh & $2.5 \pm 1.1$ & $\mathrm{Fl}$ & $3.1 \pm 1.5$ & $\mathrm{Fl}$ \\
\hline 40433 & Quincy & .L.P & $0.8 \pm 1.8$ & - & $0.6 \pm 1.6$ & Wh & $3.3 \pm 2.2$ & $\mathrm{Fl}$ \\
\hline 40440 & Westford & R..P & $1.9 \pm 1.8$ & $\mathrm{Fl}$ & - & - & $2.4 \pm 2.1$ & $\mathrm{Fl}$ \\
\hline 40442 & Fort Davis & .L.P & $0.6 \pm 1.8$ & - & $0.9 \pm 1.6$ & Wh & $4.5 \pm 2.2$ & $\mathrm{Fl}$ \\
\hline 40451 & Greenbelt & RLDP & - & - & $2.1 \pm 1.1$ & Wh & $4.4 \pm 1.6$ & $\mathrm{Wh}$ \\
\hline 40456 & Pietown & R..P & $1.1 \pm 1.8$ & - & $0.9 \pm 1.6$ & Wh & $4.0 \pm 2.2$ & $\mathrm{Fl}$ \\
\hline 40465 & North Liberty & R..P & $1.1 \pm 1.8$ & - & - & - & $4.3 \pm 2.2$ & - \\
\hline 40477 & Mauna Kea & R..P & $1.5 \pm 1.9$ & Wh & $1.3 \pm 1.6$ & $\mathrm{Fl}$ & $2.8 \pm 2.1$ & $\mathrm{Fl}$ \\
\hline 40497 & Monument Peak & .L.P & $1.3 \pm 1.8$ & - & $1.0 \pm 1.6$ & - & $3.9 \pm 2.2$ & - \\
\hline 41507 & Rio Grande &.. $\mathrm{DP}$ & - & - & $1.9 \pm 1.3$ & - & $1.8 \pm 1.7$ & - \\
\hline 41602 & Fortaleza & R..P & $2.1 \pm 1.8$ & $\mathrm{Fl}$ & $0.3 \pm 1.6$ & Wh & $3.2 \pm 2.1$ & $\mathrm{Fl}$ \\
\hline
\end{tabular}


Table 4. Site noise level (cont.).

\begin{tabular}{|c|c|c|c|c|c|c|c|c|}
\hline \multirow{3}{*}{$\begin{array}{l}\text { DOMES } \\
\text { Number } \\
41703\end{array}$} & \multirow{3}{*}{$\begin{array}{r}\begin{array}{r}\text { Site } \\
\text { name }\end{array} \\
\text { Easter Island }\end{array}$} & \multirow{3}{*}{$\begin{array}{r}\text { Techn. } \\
\text {..DP }\end{array}$} & \multicolumn{6}{|c|}{ One-year Allan deviation $(\mathrm{mm})$ and noise type } \\
\hline & & & \multicolumn{2}{|c|}{ East } & \multicolumn{2}{|c|}{ North } & \multicolumn{2}{|c|}{$U p$} \\
\hline & & & $3.1 \pm 1.7$ & - & $2.7 \pm 1.3$ & - & $3.4 \pm 1.8$ & - \\
\hline 41705 & Santiago & R.DP & $3.3 \pm 1.5$ & - & $2.4 \pm 1.3$ & $\mathrm{Fl}$ & $2.1 \pm 1.8$ & - \\
\hline 42202 & Arequipa &. $\mathrm{LDP}$ & $1.9 \pm 1.9$ & - & $1.7 \pm 1.3$ & Wh & $3.4 \pm 1.7$ & Wh \\
\hline 43201 & Sainte Croix & R..P & $1.7 \pm 1.9$ & $\mathrm{Fl}$ & $2.6 \pm 1.6$ & Wh & $4.2 \pm 2.2$ & - \\
\hline \multirow[t]{2}{*}{50103} & Canberra $a$ & R..P & $2.5 \pm 1.8$ & - & $2.8 \pm 1.6$ & $\mathrm{Wh}$ & $4.2 \pm 2.1$ & Wh \\
\hline & $b$ &. $\mathrm{LD}$ & $3.2 \pm 1.8$ & - & $3.1 \pm 1.6$ & - & $3.3 \pm 2.1$ & - \\
\hline 50107 & Yaragadee &. $\mathrm{LDP}$ & - & - & $2.5 \pm 1.1$ & $\mathrm{Fl}$ & $0.4 \pm 1.6$ & $\mathrm{Fl}$ \\
\hline 50116 & Hobart & R..P & $1.8 \pm 1.8$ & - & $2.3 \pm 1.6$ & $\mathrm{Fl}$ & $3.3 \pm 2.1$ & Wh \\
\hline 50119 & Mount Stromlo & .LD. & $3.1 \pm 1.8$ & - & $0.9 \pm 1.6$ & - & $2.5 \pm 2.1$ & - \\
\hline 50207 & Chatham & ..DP & $2.3 \pm 1.9$ & - & $1.2 \pm 1.7$ & $\mathrm{Fl}$ & $3.5 \pm 2.2$ & - \\
\hline 66006 & Syowa &.. $\mathrm{DP}$ & $2.6 \pm 1.5$ & - & $1.2 \pm 1.3$ & - & $4.3 \pm 1.8$ & - \\
\hline 66008 & O'Higgins & R..P & $3.3 \pm 1.7$ & Wh & $2.8 \pm 1.5$ & $\mathrm{Fl}$ & - & - \\
\hline 91201 & Kerguelen &.. $\mathrm{DP}$ & $3.6 \pm 1.5$ & Wh & $2.5 \pm 1.3$ & $\mathrm{Wh}$ & $3.4 \pm 1.9$ & $\mathrm{Fl}$ \\
\hline 92201 & Tahiti &. $\mathrm{LDP}$ & $2.8 \pm 1.5$ & - & $3.0 \pm 1.3$ & - & $3.4 \pm 1.8$ & - \\
\hline 92701 & Noumea & ..DP & - & - & $4.3 \pm 1.7$ & $\mathrm{Fl}$ & - & - \\
\hline
\end{tabular}

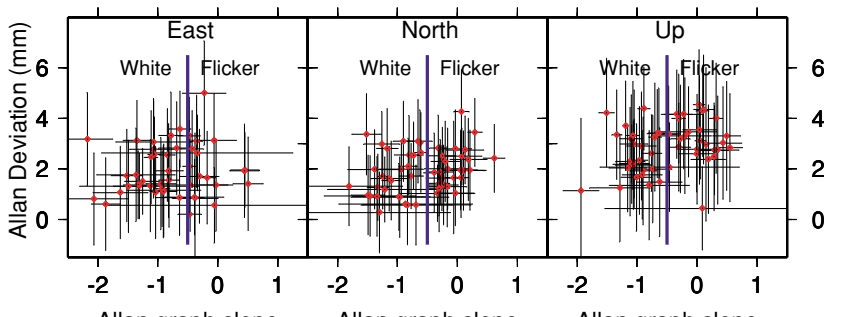

Allan graph slope Allan graph slope Allan graph slope
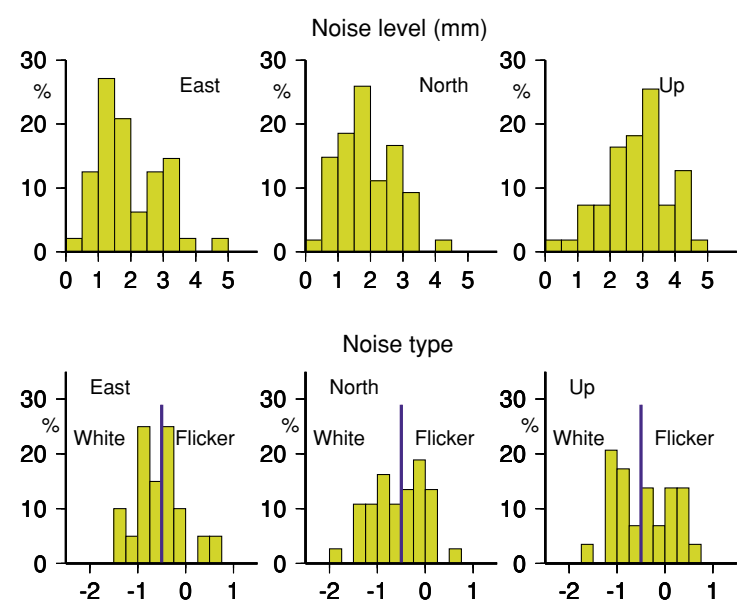

Fig. 4. Noise level and type of collocation sites. The upper graphs show the Allan deviation for the one-year sampling time as a function of the slope of the Allan graph with its spectral interpretation. The error bars are one- $\sigma$. Middle graph: distribution of noise level. Bottom graph: distribution of noise type.

range $0.5-3.5 \mathrm{~mm}$ in the East and North directions, and $1.0-4.5 \mathrm{~mm}$ in the Up direction. The noise type distribution spans the white noise and flicker noise zones, with a weak bi-modality in the North direction and a more marked one in the Up direction.

As a check of the robustness of the site noise analysis, the same least-square analysis was performed replacing the
CODE series of station position residuals by the reanalysed Wöppelmann et al. (2007) solution. The site noise level and type diagnostics are unaffected, ruling out the possibility that the presence of flicker noise GPS stations in practically all analysed sites could lead to erroneous flicker noise diagnostics for some sites.

Further investigation of the influence of various circumstances on site noise type was conducted using ANOVA (ANalysis Of VAriance between groups, Lindman, 1974). It is an inferential statistics method for testing hypotheses about the significance of the differences between more than two means. We use it here to test the relevance of proposed partitions of a population according to given conditions.

The variance of the parameter for the whole population is assumed to originate either from the scatter of individual results in each group around the group mean, or from the difference between the group mean and the global mean. If the partition is relevant, most of the variance will come from the difference between the group mean and the global mean, and the variance in each group will be much smaller. The significance test of the ratio between the variance corresponding to each of these sources involves the statistic Fisher test $F$. The significance is given in percentage. A test result significant at the $90 \%$ level means that only $10 \%$ of purely random data will show such a difference of means if the group separation is irrelevant.

The investigated parameter is the slope of the Allan graph in the East, North or Up directions. Three categories of noise type are considered, namely White, Flicker, and Indecisive. The population corresponds to the collocated sites network. The conditions for which the influence on the type of noise was tested are the maximum inter-station horizontal and vertical distances in the site, the site geographical location, and the location on stable tectonic plates or near to plate margins.

The horizontal and vertical intra-site distances was found to have no influence on the noise type. 
The influence of site location with respect to the plate margins was studied using the ITRF2000 site selection available at URL http://itrf.ensg.ign.fr/ITRF_solutions/2000/datum.php, where the set of the 95 best sites (Altamimi et al., 2002) is split into two groups: 54 sites 'located on rigid plates and far away from deforming zones' that were used for the datum definition, and 41 other sites that do not satisfy this condition. 23 and 17 sites of these respective categories belong to our list of collocation sites. This criterion was found to have no statistically significant influence on the site noise type.

Whereas the noise type in the horizontal directions was found to be unrelated to the geographical location, a high level of significance was found for the influence on the Up noise type $(99.9 \%$ for the longitude and $90.6 \%$ for the latitude). This effect corresponds to contrasting performances of two large longitude zones in the Northern hemisphere. In the geographical zone North-West of Fortaleza (Brasil) and East of Hawaii, all sites except Greenbelt (40451, VLBISLR-DORIS-GPS) exhibit flicker noise, while in the rest of the Northern hemisphere, all sites except Toulouse (10003, DORIS-GPS) exhibit white noise. Southern hemisphere sites have a balanced white-flicker noise distribution.

We checked that the noise type in all three directions is unrelated with the techniques operated in the site.

The four collocation sites with large inter-station distances (1-3 km), Reykjavik (10202, DORIS-GPS), Ny Alesund (10317, DORIS-GPS), Metsahovi (10503, DORISGPS), and Fairbanks (40408, VLBI-DORIS-GPS), tend to exhibit standard performances in noise level and type, with the following exceptions. Reykjavik has the second largest noise level of all sites in the North direction and anomalous noise type in the East direction. The noise level and noise type in the East direction could not be estimated for Metsahovi due to poor agreement of the time-series behaviour with the model of Eq. (4). Fairbanks has a large noise level in the Up direction. Considering the general scatter of the global solution, these results can hardly be considered as outliers.

The noise level is unrelated with the site latitude in the North and Up directions in both hemisphere, and in the East direction in the Southern hemisphere. In the Northern hemisphere, the East noise level is particularly low. Six sites only have a noise level larger than $2 \mathrm{~mm}$ : Borowiec (12205, SLR-GPS), Yuzhno-Sakhalinsk (12329, DORIS-GPS), Kitab (12334, DORIS-GPS), Herstmonceux (13212, SLR-GPS), Beijing (21601, SLR-GPS), and St John's (40101, DORIS-GPS).

At an early stage of data analyses, position discontinuities were not considered for some of the stations mentioned in the IGS list. Those were Borowiec (12205, SLR-GPS), Algonquin (40104, VLBI-GPS), North Liberty (40465, VLBI-GPS), Monument Peak (40497, SLR-GPS), and Easter Island (41703, DORIS-GPS). The inspection of their derived noise level and type in the local directions revealed outlying parameters that confirmed both the anomalous behaviour expected by the IGS, as well as the ability of our qualification algorithm to identify such behaviours. The IGS flags for these stations were taken into account in the final analysis (see Table 8).
The site noise levels at Herstmonceux and Westford sites, both with a most stable SLR station and where transient GPS antenna instability produced poor GPS station stability results (see Section 3.2), are not particularly high. Their noise types are consistent with the global noise type distribution.

Three sites, all of them DORIS-GPS collocation sites, had been rejected because the inter-stations distances exceed $5 \mathrm{~km}$, inferring that their residual signals could not be expected to have a common behaviour. They were nevertheless analysed separately. Their respective noise levels in the East, North and Up directions expressed in $\mathrm{mm}$ are the following.

- Ascension (30602): $1.3 \pm 2.5 ; 3.6 \pm 1.6 ; 6.2 \pm 2.7$.

- Guam (50501): $4.0 \pm 2.3 ; 2.5 \pm 1.6 ; 2.6 \pm 2.3$.

- Kourou (97301): $1.8 \pm 2.2 ; 3.1 \pm 1.6 ; 2.1 \pm 2.3$.

Except for the Up direction at Ascension, these noise levels are consistent with the distributions of Fig. 4. The formal uncertainties are generally larger than those of the other sites, which indicates a worse agreement with the model expressed by Eq. (4). The noise type is white noise for Guam in all three directions and flicker noise for Ascension and Kourou in all three directions.

\subsection{Technique noise level and type}

The results are summarized in Section 6, together with those obtained by the alternative methods described in Sections 3.2 and 4. Lines of Table 5 with heading 'Techn and site' give the noise levels and Allan graph slopes derived from the 144 stations in 56 sites studied in this section. As was the case for the results of the three-cornered hat method applied site by site, in the two cases where the fouryear variance was missing, the North direction for VLBI and SLR, the slope of the Allan graph was not considered.

The major difference between the three-cornered hat approach and the parallel estimation of technique and site noise is the hypothesis made on the signal content of the residual time-series of positions. In the former case the collocated residual time-series are assumed to include a common signal, while in the latter case, they are assumed to include only common noise level. The 'Technique and site' results are more regularly aligned than those derived by the global three-cornered hat method, coming closer to a classical Allan graph. This suggests that the data better match the weak assumption of common noise level than the strong one of common signal in collocation sites.

The data analyses in this article are based on single analysis centre time-series of positions. The IGS combined series mentioned in Section 2.1 were used as an experiment in replacement for the CODE GPS series, keeping the other three data sets unchanged. While the noise levels and types found for VLBI, SLR, and DORIS are unaffected by the replacement of the GPS data, the GPS noise levels for the one-year sampling time are $0.8 \mathrm{~mm}, 1.3 \mathrm{~mm}$, and $2.0 \mathrm{~mm}$ in the East, North, and Up directions, respectively, close to the VLBI and SLR values for a single analysis centre. The noise type diagnostic for GPS is still flicker noise in all three local directions, with some indication of noise at periods longer than five years. 

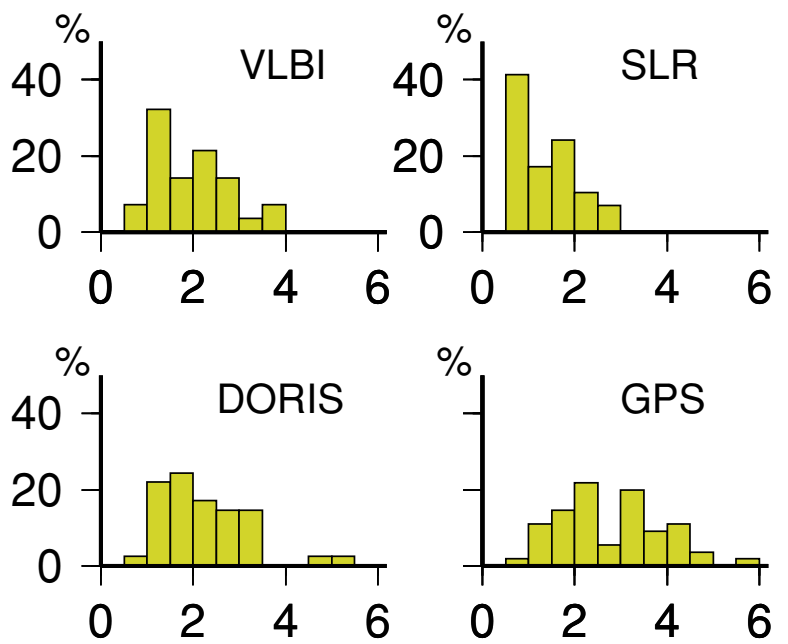

Fig. 5. Distribution of scale factors for weighting the contribution of collocated stations to a combined terrestrial reference frame.

\section{Discussion}

Each of the four methods for determining the level and type of noise using time-series of station coordinates has its strengths and weaknesses.

Considering the station noise as a whole has the advantage of assessing the very data that are used in geophysical interpretations or in terrestrial frame maintenance, independently of the observation technique. This approach may be applied to isolated stations as well as collocated ones. The interpretation of its results in terms of technique-specific noise spectrum is not straightforward. The option taken, namely selecting the median stability parameters of the best observed stations, is only one among others. The relative station quality factor $\alpha$ in Eq. (4) derived within each technique network is of great importance to adequately disentangle technique and site noise in the implementation of the fourth method.

The three-cornered-hat method is in principle a rigorous way to determine technique noise spectrum on the basis of collocated time-series, providing that the data are strong enough. Only 11 sites with three techniques, and 1 with the four techniques operated in parallel are available, so that the results may be not strong enough to be generalized. The extension of the method to the global network, no longer considering local three-cornered observation conditions, proves in some cases to be relatively unstable with respect to the sampling time.

In the fourth approach, the site noise is estimated instead of being substracted. This approach provides a more robust answer for technique noise level and type.

\subsection{Station noise}

The set of collocated stations studied in this paper is the key element in combined terrestrial reference frames such as those derived in the IERS work. The maintenance of internal consistency with time of the combined TRF depends on the stability of the sub-network of the collocated sites. Several approaches are proposed for optimizing such combinations, e.g. Altamimi and Collillieux (2007), Meisel et al. (2005).
The analyses of station stability in Sections 3.2 and 3.4 clearly show significant differences between stations and between techniques, both in noise level and in noise type. Accounting for this diversity when combining terrestrial reference frames can be expected to contribute to maintaining the internal consistency of the combined TRF.

The ITRF2000 combination, based on sets of station positions and velocities, took into account one global weight factors for each individual TRF entering into the combination (Altamimi et al., 2002). The ITRF2005 computation, which is based on time-series of station positions, also includes global weighting of the individual contributions, based on the noise level of time-series at one-week intervals (Altamimi and Collilieux, 2006). In preparation for future combination works, we suggest that the impact of station weighting be further investigated. A station weighting scheme based on the level and type of noise was proposed by Le Bail et al. (2006). It consists in multiplying the uncertainties associated with the data in the individual TRFs by a scale factor defined as the ratio of the three-dimensional one-year Allan deviation of the residual time-series, defined in Section 2, with the average three-dimensional formal uncertainty of the series. Larger scale factors indicate larger underestimations of the uncertainties associated with the data. The scale factors obtained for the stations of Table 7 are shown in Fig. 5, as an example of the application of this definition. The ranges of scale factors are $0.5-4$ for VLBI, 0.5-2 for SLR, 0.5-3 for DORIS, and 1-5 for GPS, with a few outlying large values for all techniques.

The use of this weighting scheme, or that of a similar one, would bring several improvement in the consideration of observation noise in combining data. It can be applied separately to each station, thus accounting for the various quality of the stations. It is defined independently of the observing technique, thus ensuring homogeneity of the data treatment. In addition, it is based on medium-term, rather than short-term, stability. In a white noise context the proposed weighting is independent of the sampling time, but in the case of flicker noise stations are down-weighted, which can be expected to whiten the noise of the resulting combined TRF. Note that with the currently available 10-15 years data time spans, choosing the one-year sampling time ensures robustness of the calculated weight factors.

\subsection{Site noise}

One may first note that the confrontation of the model expressed by Eq. (4) with the data is successful, with a compact distribution of estimated site noise, smoothness of technique noise estimations for the sampling times ranging from 0.25 years through 4 years, small post-fit residuals and a fairly small rate of solution failures. A number of general properties of site noise can be derived from our analysis.

The noise level, measured by the Allan deviation for the one-year sampling time of the non-linear, non-seasonal signal, is consistently found to be smaller than $3.5 \mathrm{~mm}$ in the horizontal plane, and $4.5 \mathrm{~mm}$ in height. This is true for sites with all techniques combinations. Although we found (Table 5) that the median noise level of SLR stations in height is not higher than in the horizontal plane, it is clear from Fig. 3 that a number of stations in the series used have anomalous noise in height. The noise level is the lowest 
Table 5. Technique noise level and type. Results obtained from the analysis of individual station position time-series (Section 3.2), from applying the three-cornered hat (TCH) method site by site (Section 4.1) or globally (Section 4.2), and with parallel estimation of site noise (Section 5.2).

\begin{tabular}{|c|c|c|c|c|c|c|c|}
\hline \multirow[t]{2}{*}{ Method } & \multirow[b]{2}{*}{ Section } & \multicolumn{3}{|c|}{ 1-yr Allan deviation (mm) } & \multicolumn{3}{|c|}{ Allan graph slope } \\
\hline & & East & North & $U p$ & East & North & $U p$ \\
\hline & & \multicolumn{6}{|c|}{ VLBI } \\
\hline Stations & 3.2 & 0.7 & 0.8 & 2.8 & -0.9 & -0.9 & -1.0 \\
\hline TCH /site & 4.1 & 0.9 & 1.9 & 1.9 & - & - & - \\
\hline TCH global & 4.2 & $0.3 \pm 0.1$ & $1.4 \pm 0.2$ & $1.6 \pm 0.2$ & - & $-1.3 \pm 0.6$ & $+0.4 \pm 0.3$ \\
\hline \multirow{2}{*}{ Techn and site } & 5.2 & $0.4 \pm 0.1$ & $0.5 \pm 0.1$ & $1.5 \pm 0.1$ & $-1.5 \pm 0.2$ & - & $-1.2 \pm 0.1$ \\
\hline & & \multicolumn{6}{|c|}{ SLR } \\
\hline Stations & 3.2 & 1.5 & 1.5 & 1.3 & -1.1 & -1.0 & -1.0 \\
\hline TCH / site & 4.1 & 2.0 & 2.0 & 3.6 & - & - & - \\
\hline TCH global & 4.2 & $1.3 \pm 0.3$ & $1.6 \pm 0.1$ & $3.0 \pm 0.3$ & $-1.1 \pm 0.1$ & $-1.0 \pm 0.1$ & $-1.0 \pm 0.1$ \\
\hline \multirow[t]{2}{*}{ Techn and site } & 5.2 & $1.9 \pm 0.2$ & $1.1 \pm 0.1$ & $1.3 \pm 0.1$ & $-0.8 \pm 0.2$ & - & $-1.0 \pm 0.2$ \\
\hline & & \multicolumn{6}{|c|}{ DORIS } \\
\hline Stations & 3.2 & 3.9 & 2.8 & 4.2 & -1.0 & -0.9 & -0.9 \\
\hline TCH /site & 4.1 & 4.6 & 2.3 & 3.1 & - & - & - \\
\hline TCH global & 4.2 & $4.6 \pm 0.4$ & $2.0 \pm 0.4$ & $3.6 \pm 0.7$ & $-1.2 \pm 0.3$ & $-1.0 \pm 0.1$ & $-0.7 \pm 0.2$ \\
\hline \multirow[t]{2}{*}{ Techn and site } & 5.2 & $3.5 \pm 0.3$ & $2.0 \pm 0.3$ & $3.1 \pm 0.5$ & $-0.7 \pm 0.1$ & $-0.8 \pm 0.3$ & $-0.4 \pm 0.1$ \\
\hline & & \multicolumn{6}{|c|}{ GPS } \\
\hline Stations & 3.2 & 2.5 & 4.2 & 4.4 & -0.3 & -0.3 & -0.4 \\
\hline TCH /site & 4.1 & 1.8 & 3.9 & 3.3 & - & - & - \\
\hline TCH global & 4.2 & $3.3 \pm 0.5$ & $2.9 \pm 0.5$ & $3.6 \pm 0.7$ & $-0.9 \pm 0.4$ & $-0.7 \pm 0.1$ & $-0.4 \pm 0.1$ \\
\hline Techn and site & 5.2 & $1.7 \pm 0.2$ & $3.4 \pm 0.3$ & $2.8 \pm 0.3$ & $+0.6 \pm 0.3$ & $-0.1 \pm 0.1$ & $-0.4 \pm 0.1$ \\
\hline
\end{tabular}

for the East direction in the Northern hemisphere. No other latitude effect on noise level is visible.

The examination of the noise type contribution to site stability opens a number of interesting questions. White noise is dominant in the East direction. As the few non white noise sites have no obvious common character, the explanation for this anomaly may hopefully be found in local observing conditions. The East direction also gets the largest number of sites that do not match the model (16\% vs $4-5 \%$ in the other two directions), maybe due to a worse DORIS stability and a better VLBI one. A remarkable structure in the Up noise type is pointed out but not explained, namely a bimodal longitude distribution of noise type in the Northern hemisphere.

\subsection{Technique noise}

The evaluations derived in Sections 3.2, 4, and 5 for the technique-specific noise in station motion measurement are summarized in Table 5 and plotted in Fig. 6. Considering the differences in the assumptions and in the computation methods, the agreement of the results of the four approaches is remarkable. The assumption of uncorrelated non-linear, non-seasonal signals in collocated time-series is comforted by the analysis of our results. We therefore conclude that the 'Technique and Site' method is the most appropriate for qualifying the technique noise.

The most probable values of the technique noise level and type are listed in Table 6 . The noise level values adopted are in each case the lowest of the median station noise level and the site noise level found by the Technique and Site method, considering that the technique noise level should not be higher than that of its least stable stations, considering the well observed stations. To take into account the specific problems in the North-South direction for the considered GPS solution, we adopt a final value deduced from our parallel analyses of the CODE and IGS solutions.

The noise levels of Table 6 show a clear ranking between the techniques, that may be expressed by the threedimensional noise level for the one-year sampling time: $1.7 \mathrm{~mm}$ for VLBI, $2.7 \mathrm{~mm}$ for SLR, $5.2 \mathrm{~mm}$ for DORIS, $4.1 \mathrm{~mm}$ for GPS (operational), and $1.8 \mathrm{~mm}$ for GPS (reanalysed).

The ratio of the height noise level to the average horizontal noise level is equal to 1.7 for VLBI, 0.6 for SLR, 0.8 for DORIS, and $0.7-0.9$ for GPS. The noise in the Up direction is known to be higher than in the horizontal for the radio electric techniques (VLBI, DORIS, GPS) because of the difficulty in modelling the signal delay by the troposphere. As this defect is reflected only in the VLBI case, one may wonder whether the site noise level has absorbed this effect, which is common to all techniques whenever SLR is not present, i.e. about $2 / 3$ of the sites. The median ratio for the sites is equal to 1.1 , with eight sites having a ratio larger than 1.5. This suggests that the site noise parameters may indeed have absorbed some of this environment-related noise, and that VLBI may have other specific causes for exaggerated vertical noise.

On the other hand, the GPS series used may still contain signal reflecting interannual variations in the scale of the underlying terrestrial reference frame (see Section 2.1) that could be interpreted in our analysis as noise in the Up direction. The low ratio found indicates that such effect is not present in the station motion residual signal. 

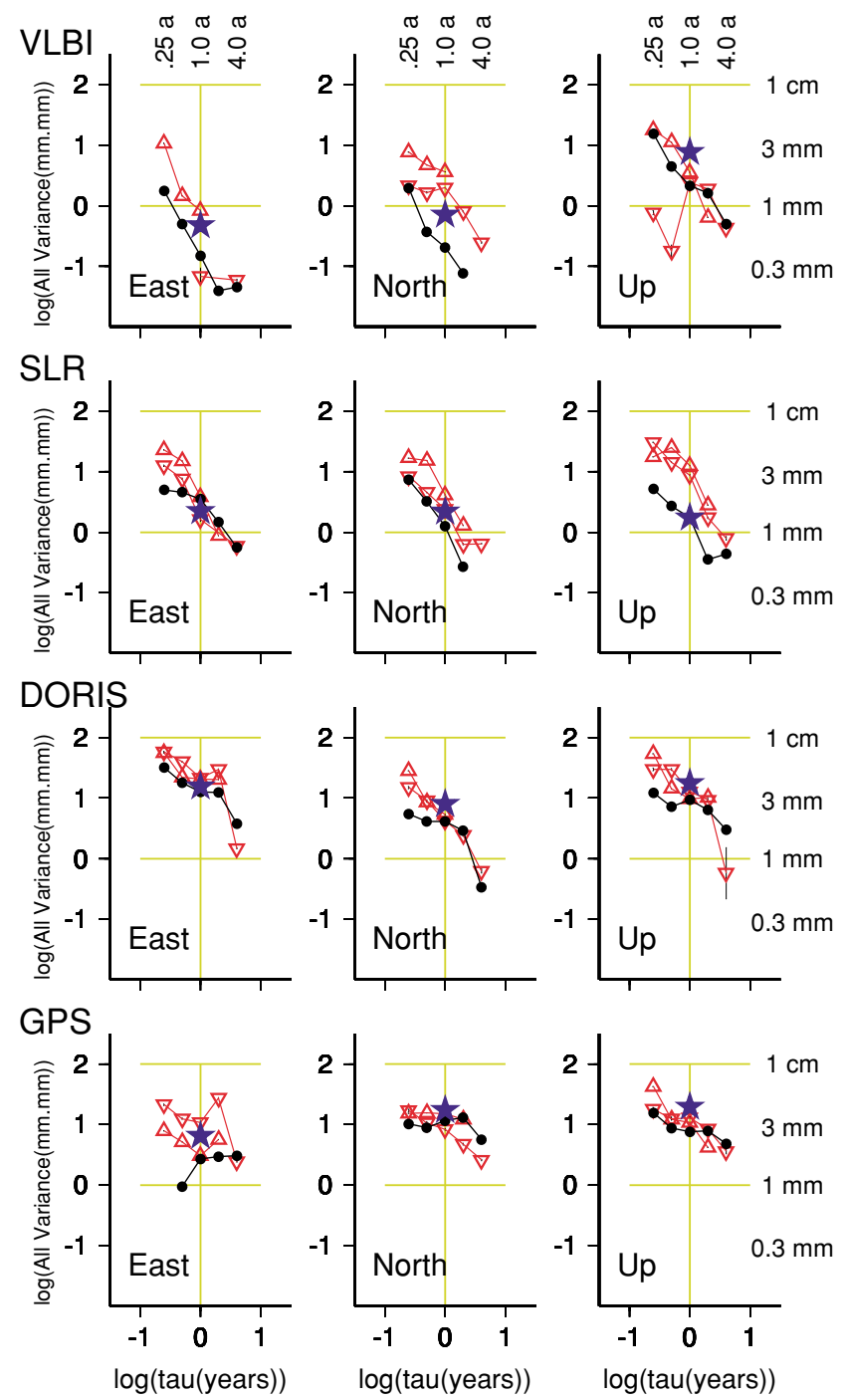

Fig. 6. Allan graphs of technique noise. Results obtained from the analysis of individual station position time-series (stars, Section 3.2), from applying the three-cornered hat $(\mathrm{TCH})$ method site by site (triangles, Section 4.1) or globally (inverted triangles, Section 4.2), and with parallel estimation of site noise (filled circles, Section 5.2). A slope -1 is the signature of white noise; a slope equal to 0 is the signature of flicker noise.

When replacing the GPS series by the IGS combined one in the computation, the ratio of the height noise level to the average horizontal noise level for GPS is nearly doubled (1.3 instead of 0.7 ) and the median for the sites is lessened (0.9 instead of 1.1), meaning that the lower stability in the Up direction is correctly ascribed to the technique and its modelling problem, and not globally to the sites. These partial results give reasons to apply this type of analysis to technique-specific combined time-series of station positions when they will be available for all four techniques.

The conclusions on the noise type summarized in Table 6 are straightforward for what concerns general white noise for VLBI and SLR, in close agreement with the station statistics illustrated by Fig. 3. In the DORIS case, the technique noise statistics of Table 5 and Fig. 6 are somewhat less clear. We conclude that the horizontal noise is probably white, whereas we cannot conclude about the type of vertical noise. We find here an echo of the partial dis- agreement between Williams and Willis (2006), who model the DORIS positioning noise as a balanced mix of white noise with time-varying amplitude and flicker noise, and Le Bail (2006) who qualifies it mainly as white noise, with a few stable high latitude stations exhibiting flicker noise. The GPS noise type is flicker noise in the horizontal directions and indecisive in the Up direction. As in the DORIS case, these conclusions are only partly in agreement with those of Williams et al. (2004), whose diagnostic for the SOPAC Reanalysis Global Solution is a mix of white noise and flicker noise. Note that, while the analysis method used by the latter group consists of estimating globally the noise levels for a given mix of noise spectra (here white noise and flicker noise) by a maximum likelihood estimation, in this study we derive global characteristics from single station analysis, and we consider in addition a site contribution to the noise level and type. Given these differences in analysis approaches, the conclusions of the two studies concerning the noise spectrum are not in contradiction.

\section{Conclusions}

Several analysis methods were applied to collocated time-series of positions in 60 sites monitored by the four global geodetic techniques, VLBI, SLR, DORIS and GPS in order to evaluate their long term positioning stability. The stability estimations were based on statistics of the nonlinear, non-seasonal residual motion described by station position time-series. Stability is described by two parameters: the noise level, defined as the Allan deviation of the time-series for the one-year sampling time, and the noise type, derived from the examination of the change of the Allan variance with the sampling times. The method which best fits the data behaviour comforts the assumption that the collocated residual time series do not include a significant common signal, but rather a site-characteristic noise. It gives estimates of the level and type of noise for the sites as well as for each of the geodetic techniques, showing that the part of the signal rejected in geodetic and geophysical applications can be useful to better understand the dominant signal.

The first conclusion reached from the detailed study of about 150 station position time-series is the recognition of the excellent quality of the measurements and the homogeneous stability of the collocation sites. Analysts can appreciate the quality of the work of geodesists and institutions that have set up the networks, installed the stations and maintain them, over decades already. One must also recognize the role of the IERS and the associated international services in fostering the permanent improvement of results, and making state-of-the-art data easily available.

This study is based only on single analysis centres solutions, to ensure fair comparison of the geodetic techniques. It is clear that the analysis method should be applied to a set of technique-combined residual time-series when they will be available, as is expected after the release of ITRF2005. The results obtained then should be more robust.

We introduced the concept of site noise. Its meaning is wide, as it includes possible local geophysical instabilities, as well as equipment or building problems, or analysis deficiencies that would be common to the geodetic techniques 
Table 6. Technique noise level and type for single analysis centre solutions.

\begin{tabular}{l|ccc|ccc}
\hline \multirow{2}{*}{ Technique } & \multicolumn{2}{c}{ 1-yr Allan Deviation (mm) } & \multicolumn{3}{c}{ Spectrum } \\
& East & North & $U p$ & East & North & White \\
\hline VLBI & 0.4 & 0.8 & 1.5 & White & White & White \\
SLR & 1.5 & 1.5 & 1.3 & White & White & Indecisive \\
DORIS & 3.6 & 2.0 & 3.1 & White & White & Indecisive \\
\multicolumn{1}{c}{ OpS } & & & & & Flicker & Mostly White \\
\hline
\end{tabular}

operated. Its level is found to be consistently lower than $3.5 \mathrm{~mm}$ horizontal and $4 \mathrm{~mm}$ vertical. The noise type distribution includes white noise as well as flicker noise. It is unrelated with the horizontal or vertical inter-station distances within a site, or with the fact that a site is close to a tectonic plate margin or not, or with geographical location, except in the Up direction: in a large geographical sector from North Pacific through North-East Brasil, all sites except one exhibit flicker noise, whereas all other North hemisphere sites except three have white noise. In the Southern hemisphere, the noise type is unrelated with the site longitude. The flicker noise signature is deficient in the East direction, in the same time that the noise type could not be estimated for a relatively large proportion of the sites $(20 \%$, as compared with $7 \%$ and $3 \%$ in the North and Up directions). This may be related to a larger scatter of the geodetic techniques performance in this direction. The general noise level is related to the observation noise level. Using combined solutions for all the techniques might lead to smaller noise levels.

The concept of geodetic technique noise used here includes the effects of a number of operational and analysis effects, such as the actual operation of the stations, the network configuration and satellite constellation and their evolution in time, the modelling of the effects relative to the stations, the extraterrestrial emitters or targets, and the transmitting media. What we measure is to some extent dependent on the specific solution selected. Although the thinking behind the data selection aimed at getting "representative" solutions for each technique given the availability conditions, some conclusions may be taken with caution, in particular in the GPS case. Having said that, the ranking of the techniques noise levels and the qualification of their noise types are quite robust. They are not expected to be drastically modified when combined series will be used.

The most stable technique is VLBI, with $0.9 \mathrm{~mm} 2 \mathrm{D}$ noise level for the one-year sampling time in horizontal and $1.5 \mathrm{~mm}$ in vertical. SLR noise in vertical is at the same level $(1.3 \mathrm{~mm})$, and a horizontal 2D noise level of $2.1 \mathrm{~mm}$. We may infer from this similar stability in height that both techniques are equally able to maintain the long term stability of the scale of the combined terrestrial reference frame that they define jointly. DORIS and GPS form a second stability group, with $4.1 \mathrm{~mm}$ and $3.1 \mathrm{~mm}$ horizontal 2D noise, $3.1 \mathrm{~mm}$ and $2.7 \mathrm{~mm}$ vertical noise, respectively. The noise type in all three local directions is white noise for VLBI and SLR. The GPS spectrum is flicker noise in the horizontal directions and indecisive in vertical. The DORIS signature is white noise in the horizontal directions and indecisive in vertical.

Concerning GPS, we showed that the analysis circumstances in the long run has a strong influence on both the level and type of noise. In the case of the tested reanalysed solution derived by Wöppelmann et al. (2007), the noise level reaches the best levels of all four techniques, namely the VLBI level in horizontal and to the SLR level in vertical. In addition, the percentage of stations with flicker noise drops to only about $20 \%$ of the network.

The study presented here led to new results on the long term noise structure of space-geodetic positioning. The Allan variance approach was shown to be appropriate to derive robust qualification of the noise spectrum of the measuring techniques, which should help when deriving geophysical interpretations of the station motion signal. One may be looking forward to the application of the 'Technique and Site' analysis approach for qualifying the combined timesseries derived by the international services for VLBI, SLR, DORIS, and GPS. It is also suggested that the proposed weighting scheme based on long-term station stability be tested for their combination into a multi-technique terrestrial reference frame.

Acknowledgments. We thank Chopo Ma and Karen Baver (GSFC) for providing us with time-series of VLBI station positions, and David Coulot (IGN/LAREG) and Philippe Berio (OCA) for providing time-series of SLR station positions. The DORIS time-series of positions provided by Laurent Soudarin were referred to ITRF2000 by Jean-Jacques Valette (CLS/IDS Central Bureau) using the CATREF software. We are most thankful to Rémi Ferland (IGS) and Urs Hugentobler (AIUB) for helping us to better understand the subtleties of GPS positioning results, to Zuheir Altamimi (IGN/LAREG) and David Coulot for discussing the founding concepts of our analyses, and to Xavier Collilieux (IGN/LAREG) for documentation about seasonal station position changes. The website of the IERS/ITRS Centre http://itrf.ensg.ign.fr/ was extensively used to get information about the IERS multi-technique terrestrial network. We thank Jim Ray and the second, anonymous, referee for comments and suggestions that helped us to clarify the concepts and methods we use, and the significance of the results obtained. This paper is IPGP contribution \#2203. The first author dedicates this work to Bernard Guinot. While he was setting the theoretical foundations of the stability algorithm still in use for the derivation of the international atomic time TAI, he embarked her in the statistics of time-series of astro-geodetic station positions. This was back in the 1960's, when the beautiful space-geodetic results analysed here were still dreams for the future. 
Table 7. Collocated time-series. The dates of the first and last normal 91-d point are given.

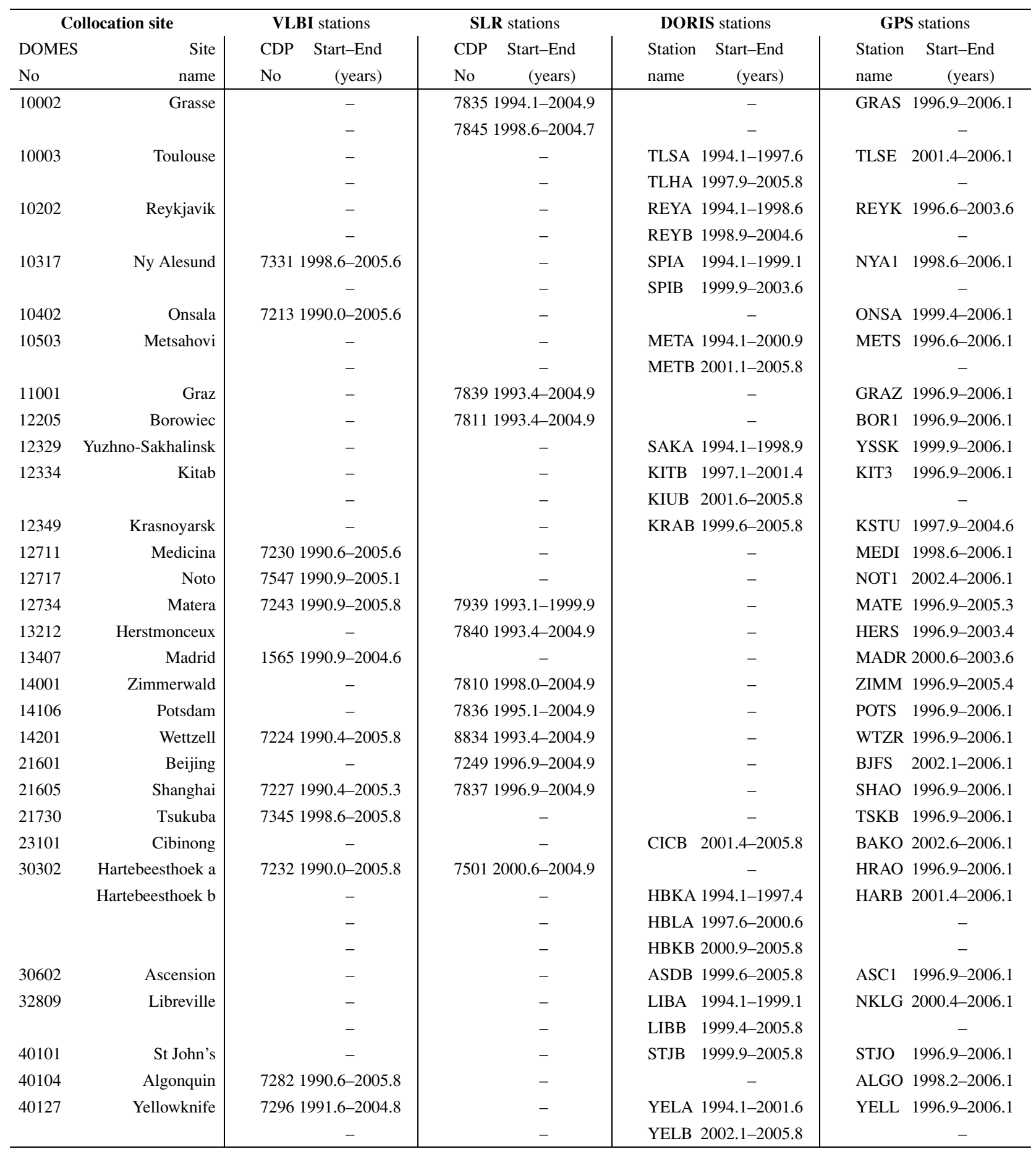

\section{Appendix}

\section{A.1 Data Selection}

The data analysed are sets of time-series of local station East (longitude), North (latitude) and Up (vertical) coordinates.

The data selection conditions of the analysis are the following.

- Primary station selection: the station is selected for analysis if it satisfies the following conditions:

1) Series duration longer than 3.1 years.

2) Total percentage of edited points in the three E, N, U directions lower than $30 \%$.
The list of stations that passed this first selection and which data are analysed in this paper is given in Table 7.

- Secondary station selection. Some stations that pass the above selection still have a data configuration that may weaken the analysis. The conditions to be satisfied for this secondary selection are as follows.

1) Largest data gap spanning less than 200 days.

2) Number of yearly averages larger than or equal to 4 .

Their results are not considered to qualify the station performances (first line of Table 5).

\section{A.2 Data Editing}

The control of discontinuities in time-series of sta- 
Table 7. Collocated time-series (cont.).

\begin{tabular}{|c|c|c|c|c|c|c|c|}
\hline \multicolumn{2}{|c|}{ Collocation site } & VLBI stations & SLR stations & \multicolumn{2}{|c|}{ DORIS stations } & \multicolumn{2}{|c|}{ GPS stations } \\
\hline $\begin{array}{l}\text { DOMES } \\
\text { No }\end{array}$ & $\begin{array}{r}\text { Site } \\
\text { name }\end{array}$ & $\begin{array}{lr}\text { CDP } & \text { Start-End } \\
\text { No } & \text { (years) }\end{array}$ & $\begin{array}{lr}\text { CDP } & \text { Start-End } \\
\text { No } & \text { (years) }\end{array}$ & $\begin{array}{l}\text { Station } \\
\text { name }\end{array}$ & $\begin{array}{r}\text { Start-End } \\
\text { (years) }\end{array}$ & $\begin{array}{l}\text { Station } \\
\text { name }\end{array}$ & $\begin{array}{r}\text { Start-End } \\
\text { (years) }\end{array}$ \\
\hline 40405 & Goldstone & $15151998.4-2004.6$ & - & GOMB & $1998.4-2004.0$ & GOLD & 1998.4-2006.1 \\
\hline 40408 & Fairbanks & $72251990.0-2002.9$ & - & FAIA & $1994.1-1999.4$ & FAIR & 1996.9-2002.9 \\
\hline & & - & - & FAIB & $2000.0-2002.9$ & & - \\
\hline 40424 & Kokee & $13111990.0-1994.1$ & - & KOKA & $1994.1-2002.9$ & КОКВ & 1996.9-2001.9 \\
\hline & & $72981993.6-2005.8$ & - & & - & & - \\
\hline 40433 & Quincy & - & $71091993.1-1997.4$ & & - & QUIN & 1998.4-2006.1 \\
\hline 40440 & Westford & $72091992.1-2005.3$ & - & & - & WES2 & 1996.9-2002.6 \\
\hline 40442 & Fort Davis & $76131993.1-2005.3$ & $70801993.4-2004.9$ & & - & MDO1 & 1996.9-2006.1 \\
\hline 40451 & Greenbelt & 7108 1993.6-2002.4 & $71051993.4-2004.9$ & GREB & 2000.9-2005.6 & GODE & 1996.9-2006.1 \\
\hline 40456 & Pietown & $72341990.4-2005.3$ & - & & - & PIE1 & 1996.9-2006.1 \\
\hline 40465 & North Liberty & $76121992.6-2005.3$ & - & & - & NLIB & 1996.9-2005.3 \\
\hline 40477 & Mauna Kea & 7617 1993.6-2005.3 & - & & - & MKEA & 1996.9-2006.1 \\
\hline 40497 & Monument Peak & - & $71101999.8-2003.4$ & & - & MONP & $1999.8-2006.1$ \\
\hline 41507 & Rio Grande & - & - & RIOB & 1995.4-2000.9 & RIOG & 1999.9-2006.1 \\
\hline & & - & - & RIPB & 2001.4-2005.8 & & - \\
\hline 41602 & Fortaleza & $72971993.4-2005.8$ & - & & - & FORT & 1996.9-2006.1 \\
\hline 41703 & Easter Island & - & - & EASA & 1994.1-2000.9 & EISL & 1996.9-2003.1 \\
\hline & & - & - & EASB & 2001.9-2005.8 & & - \\
\hline 41705 & Santiago & 1404 1991.9-1996.9 & - & SANB & 2001.6-2005.8 & SANT & 1996.9-2006.1 \\
\hline 42202 & Arequipa & - & $74031993.1-2001.4$ & AREA & $1994.1-2001.4$ & AREQ & 1996.9-2001.4 \\
\hline 43201 & Sainte Croix & $76151993.6-2005.3$ & - & & - & CRO1 & 1996.9-2005.1 \\
\hline 50103 & Canberra a & $15451990.0-2005.6$ & - & & - & TIDB & 1996.9-2006.1 \\
\hline & Canberra $b$ & - & $78431993.4-1998.9$ & ORRA & $1993.1-1996.2$ & & - \\
\hline & & - & - & ORRB & 1997.0-1998.8 & & - \\
\hline 50107 & Yaragadee & - & $70901993.4-2004.9$ & YARA & 1994.1-1999.6 & YAR1 & 1997.9-2006.1 \\
\hline & & - & - & YARB & 1999.9-2003.9 & & - \\
\hline 50116 & Hobart & $72421990.4-2005.6$ & - & & - & HOB2 & 1996.9-2006.1 \\
\hline 50119 & Mount Stromlo & - & $78491998.4-2002.9$ & MSOB & 1999.4-2002.9 & & - \\
\hline 50207 & Chatham & - & - & CHAB & 1999.4-2005.2 & CHAT & 1996.9-2006.1 \\
\hline 50501 & Guam & - & - & GUAB & $1994.1-2000.6$ & GUAM & 1996.9-2006.1 \\
\hline 66006 & Syowa & - & - & SYOB & $1994.1-1998.1$ & SYOG & 2000.4-2006.1 \\
\hline & & - & - & SYPB & $1999.1-2005.8$ & & - \\
\hline 66008 & O’Higgins & $72451993.4-2004.8$ & - & & - & OHIG & 1996.9-2002.1 \\
\hline & & - & - & & - & $\mathrm{OHI} 2$ & 2002.4-2006.1 \\
\hline 91201 & Kerguelen & - & - & KERB & 1995.1-2001.1 & KERG & 1996.9-2006.1 \\
\hline & & - & - & KESB & 2001.6-2005.8 & & - \\
\hline 92201 & Tahiti & - & $71241998.1-2004.9$ & PAQB & 1998.9-2005.8 & THTI & 1999.6-2006.1 \\
\hline 92701 & Noumea & - & - & NOUA & 1994.1-2000.4 & NOUM & $1998.4-2006.1$ \\
\hline 97301 & Kourou & - & - & KRUB & $1994.1-2005.8$ & KOUR & 1996.9-2005.3 \\
\hline
\end{tabular}

tion coordinates is a network maintenance concern for all techniques. The respective services maintain lists of station discontinuities. Whenever justified by the inspection of the series of 91-day residuals, the indications of the IGS list of confirmed discontinuities (ftp macs.geod.nrcan.gc.ca/pub/requests/sinex/discontinuities) and those of the IDS list (ftp://ftp.cls.fr/pub/ids/stations/station_events.txt) were used to delete data, keeping the longest collocated series before or after the reported discontinuity date. The discontinuities considered are listed in Table 8. Some comments follow.

- The following IGS-mentioned discontinuities for GPS stations were not considered because the series of 91-d residual East, North, and Up coordinates showed no anomalous discontinuities at this date. These are: Goldstone (GOLD), Hector Mine Earthquake at 1999.8; Greenbelt (GODE) unknown cause at 1998.2; Grasse (GRAS), antenna and receiver change at 2004.8; Guam (GUAM), Mariana Islands Earthquake at 2002.3. In addition, two stations with noted transient instabilities were kept to avoid loosing the complete series: Herstmonceux (HERS), antenna problem (1999.3-2001.6) and Westford (WES2), suspected monument instability (2001.6-2002.6).

These data also provide an opportunity to test the sensitivity of our stability assessment.

- In order to extend the collocation time spans in the Fair- 
Table 8. Data editing.

\begin{tabular}{|c|c|c|c|c|}
\hline \multirow{2}{*}{$\begin{array}{l}\text { DOMES } \\
\text { No }\end{array}$} & \multirow[t]{2}{*}{ Site } & \multirow[t]{2}{*}{ Technique(s) } & Data span kept & \multirow[t]{2}{*}{ Comment } \\
\hline & & & Start & \\
\hline 10002 & Grasse & SLR & $1995.0-$ & This study \\
\hline 10402 & Onsala & GPS & $1999.1-$ & IGS: Equipment change \\
\hline 12205 & Borowiec & GPS & $1999.4-$ & IGS: Equipment change \\
\hline 12329 & Yuzhno-Sakhalinsk & DORIS & -1999.0 & This study \\
\hline 13407 & Madrid & GPS & $2000.5-$ & IGS: Equipment change \\
\hline 14001 & Zimmerwald & SLR & $1998.0-$ & This study \\
\hline 21601 & Beijing & SLR & $1999.0-$ & This study \\
\hline 21605 & Shanghai & SLR & $1996.5-$ & This study \\
\hline 40104 & Algonquin & GPS & $1998.2-$ & IGS: 'Unknown' \\
\hline \multirow[t]{3}{*}{40405} & Goldstone & VLBI & $1998.2-$ & This study \\
\hline & & DORIS & -2004.0 & This study \\
\hline & & GPS & $1998.2-$ & IGS: ‘Unknown’ \\
\hline 40408 & Fairbanks & VLBI, DORIS, GPS & -2002.8 & Delani Earthquake \\
\hline 40424 & Kokee & GPS & -2002.7 & IGS: Equipment change \\
\hline 40433 & Quincy & GPS & $1998.3-$ & IGS: Equipment change \\
\hline 40451 & Greenbelt & VLBI & -2002.6 & This study \\
\hline 40465 & North Liberty & GPS & -2005.3 & IGS: Equipment change \\
\hline 40497 & Monument Peak & SLR, GPS & $1999.8-$ & Hector Mine Earthquake \\
\hline 41703 & Easter Island & GPS & -2003.1 & IGS: Equipment change \\
\hline 42202 & Arequipa & SLR, DORIS, GPS & -2001.5 & Arequipa Earthquake \\
\hline 50107 & Yaragadee & GPS & $1997.7-$ & This study \\
\hline 50207 & Chatham & DORIS & -2005.2 & This study \\
\hline 92201 & Tahiti & GPS & $1999.3-$ & This study \\
\hline
\end{tabular}

banks and Canberra sites, the data from the pairs of successive DORIS stations-FAIA, FAIB and ORRA, ORRB, respectively-were aligned to each other and considered as a single series.

Guam (GUAM), Mariana Islands Earthquake at 2002.3. In addition, two stations with noted transient instabilities were kept to avoid loosing the complete series: Herstmonceux (HERS), antenna problem (1999.3-2001.6) and Westford (WES2), suspected monument instability (2001.6-2002.6).

These data also provide an opportunity to test the sensitivity of our stability assessment.

- In order to extend the collocation time spans in the Fairbanks and Canberra sites, the data from the pairs of successive DORIS stations-FAIA, FAIB and ORRA, ORRB, respectively-were aligned to each other and considered as a single series.

\section{A.3 Station Stability}

As explained in Section 3.1, the slope of the Allan graph, i.e., the dependence of the Allan variance on the sampling time, both in logarithmic scale, is used to qualify the stability power spectrum of the signal. The behaviour of the Allan variance is exemplified in Fig. 7 for one station from each of the techniques. The corresponding computed Allan graph slopes are listed in Table 9. The stations were selected to illustrate the typical behaviour of their technique.

As the collocated sub networks are used to infer general conclusions on the performance of the various techniques for long term positioning, it is necessary to check whether the studied stations provide representative samples of their
Table 9. Allan graph slopes for the time series of position residuals plotted in Fig. 7.

\begin{tabular}{ll|lrc}
\hline Technique & Station & East & North & Up \\
\hline VLBI & Westford & $-0.8 \pm 0.1$ & $-0.7 \pm 0.2$ & $-0.7 \pm 0.1$ \\
SLR & Yaragadee & $-1.3 \pm 0.3$ & $-1.2 \pm 0.3$ & $-0.9 \pm 0.2$ \\
DORIS & Fairbanks & $-0.8 \pm 0.2$ & $-1.7 \pm 0.7$ & $-1.1 \pm 0.4$ \\
CODE & Kerguelen & $-0.1 \pm 0.1$ & $-0.3 \pm 0.3$ & $0.0 \pm 0.2$ \\
\hline
\end{tabular}

respective techniques. To this end, we use as station quality marker the stability index defined by Le Bail et al. (2006). This stability index is a linear combination of the stability parameters introduced in Section 3.1. It reflects both the medium-term stability and stability expectation. With the weight balance adopted for the construction of the stability index, the major contribution comes from the noise level at the one year interval, while the presence of flicker noise degrades the stability index. The histograms of the stability indices for the complete networks and for their respective collocated samples are plotted on Fig. 8. For each of the four techniques the stability distribution of the collocated stations (upper graph) is close to that of the whole network (lower graph). One conclude that the set of collocated stations represents an acceptable proxy for the complete network.

Figure 9 shows the cross-correlation of the stability indices of collocated stations for the six pairs of techniques. The VLBI stations are the most stable ones, with the excep- 

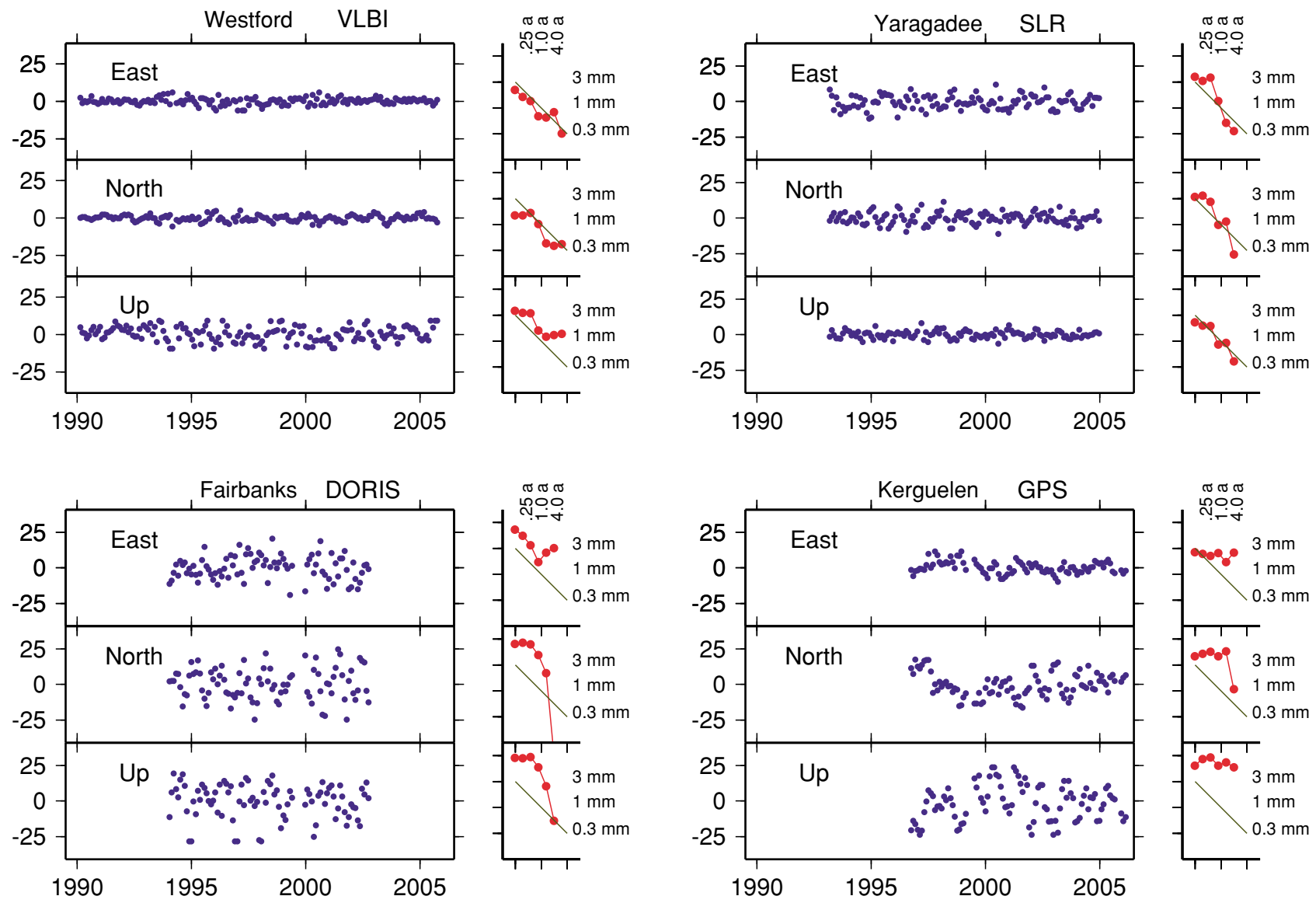

Fig. 7. Examples of time series of station position residuals at 35-day intervals over 1990-2006 (left parts, unit: mm), considering one station for each observing technique. The Allan variance is plotted as a function of the sampling time, both in logarithmic scales (Allan graphs), on the right-hand parts of the figure. The corresponding values, in years and in mm respectively, are printed. The solid line with slope -1 corresponds to white noise with a stability level of one millimetre for the one-year sampling time. The actual slopes of the Allan graphs are listed in Table 9.

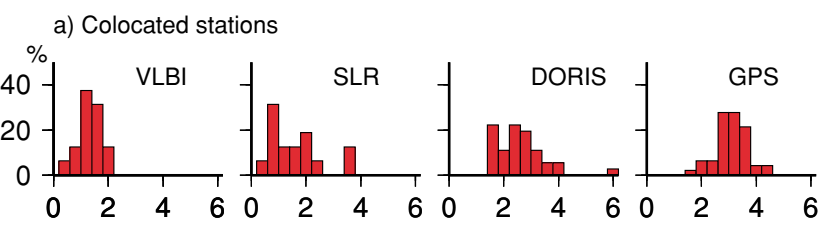

b) Whole network

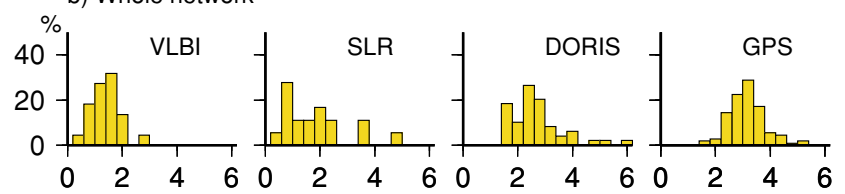

Fig. 8. Stability index distributions of studied stations and in the complete network. Small values of the stability index are for the most stable stations.

tion of Greenbelt, seen as an outlier in the comparisons with SLR, DORIS and GPS, and O'Higgins, seen as an outlier in the comparison with GPS. Then come the SLR stations, except for a few that are less stable, as seen in the SLR-GPS comparison: Borowiec, Matera, Shanghai, and Beijing, in decreasing order of stability. The DORIS and GPS stability indices are better balanced and more correlated than in the other pairs of techniques. Their correlation coefficient is close to one, suggesting common sensitivity to site effects.
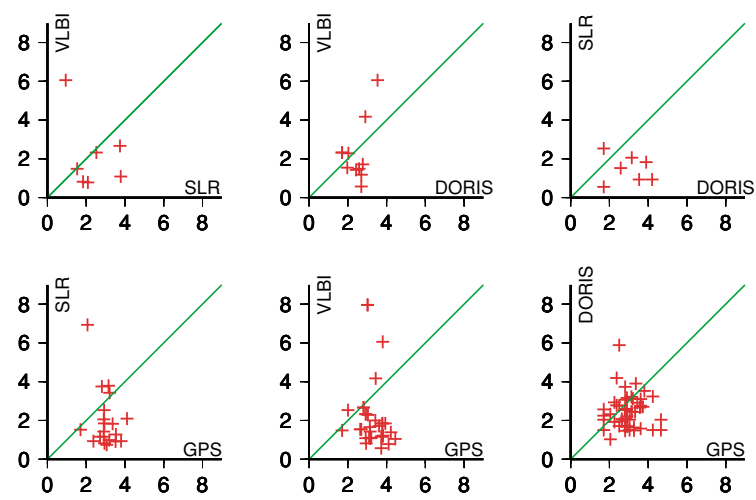

Fig. 9. Compared stability indices of collocated stations. Small values of the stability index are for the most stable stations.

\section{A.4 Selecting Collocation Sites with Expected Com- mon Behaviour}

The span of distances between two stations in a collocation site is illustrated in Fig. 10. The intra-site distances range from a few metres to kilometres. We select the stations that are close enough to each other to justify the assumption of a site-specific behaviour. Some sites or stations are treated in a peculiar way, for reasons explained hereafter. 
Table 10. Length of time-series of positions in sites with stations operated by at least three techniques. Unit: years.

\begin{tabular}{|c|c|c|c|c|c|c|c|}
\hline \multicolumn{2}{|c|}{ Collocation sites } & \multicolumn{6}{|c|}{ Pairs of techniques } \\
\hline $\begin{array}{l}\text { DOMES } \\
\text { number }\end{array}$ & $\begin{array}{r}\text { Site } \\
\text { name }\end{array}$ & $\begin{array}{l}\text { VLBI } \\
\text { SLR }\end{array}$ & $\begin{array}{c}\text { VLBI } \\
\text { DORIS }\end{array}$ & $\begin{array}{l}\text { VLBI } \\
\text { GPS }\end{array}$ & $\begin{array}{c}\text { SLR } \\
\text { DORIS }\end{array}$ & $\begin{array}{l}\text { SLR } \\
\text { GPS }\end{array}$ & $\begin{array}{c}\text { DORIS } \\
\text { GPS }\end{array}$ \\
\hline 10317 & Ny Alesund & & 9.2 & 7.7 & & & 5.5 \\
\hline 12734 & Matera & 7.0 & & 9.0 & & 3.5 & \\
\hline 14201 & Wettzell & 12.0 & & 9.5 & & 8.5 & \\
\hline 21605 & Shanghai & 8.5 & & 9.0 & & 8.5 & \\
\hline 30302 & Hartebeesthoek $a$ & 4.5 & & 9.5 & & 4.5 & \\
\hline 40127 & Yellowknife & & 11.2 & 8.5 & & & 9.5 \\
\hline 40408 & Fairbanks & & 9.2 & 6.5 & & & 6.5 \\
\hline 40424 & Kokee & & 9.2 & 5.5 & & & 5.5 \\
\hline 40451 & Greenbelt & 9.2 & 2.0 & 6.0 & 4.5 & 8.5 & 5.2 \\
\hline 42202 & Arequipa & & & & 7.7 & 5.0 & 5.5 \\
\hline 50107 & Yaragadee & & & & 10.2 & 7.5 & 6.5 \\
\hline 92201 & Tahiti & & & & 6.2 & 5.5 & 6.7 \\
\hline
\end{tabular}
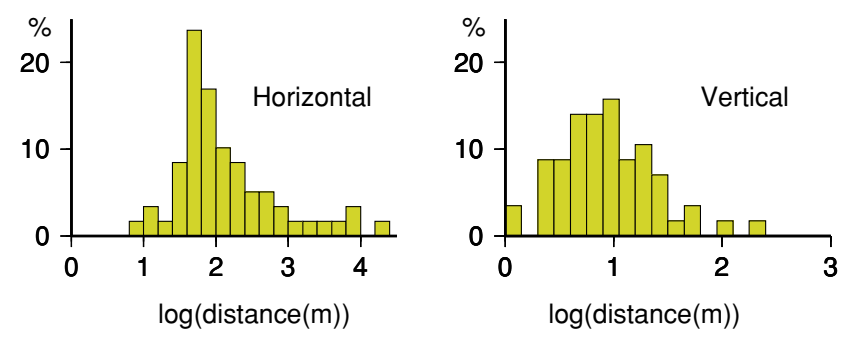

Fig. 10. Distribution of maximum horizontal and vertical distances in collocation sites.

The following stations are not considered.

- Fort Davis: the VLBI station, located $8 \mathrm{~km}$ away from the SLR-GPS observation complex.

- Goldstone: the DORIS stations, located 10 to $22 \mathrm{~km}$ away from the VLBI-GPS observation complex.

- Greenbelt: the USNO GPS station, located $20 \mathrm{~km}$ away from the VLBI-SLR-DORIS-GPS observation complex.

- Santiago: the DORIS SANA station, observed over 19931996, located $30 \mathrm{~km}$ away from the VLBI-DORIS-GPS observation complex.

The following three sites are not considered.

- Ascension: the DORIS and GPS stations are located 10 $\mathrm{km}$ away from each other.

- Guam: the DORIS and GPS stations are located $7 \mathrm{~km}$ away from each other.

- Kourou: the DORIS and GPS stations are located $25 \mathrm{~km}$ away from each other.

The following two sites are split into two sub-sites.

- Canberra: sub-site Canberra $a$ with the VLBI and GPS stations, and sub-site Canberra $b$ with the SLR and DORIS stations. Distance: $27 \mathrm{~km}$.

- Hartebeesthoek: sub-site Hartebeesthoek $a$ with VLBI, SLR and the HRAO GPS station, and sub-site Hartebeesthoek $b$ with the DORIS stations and the HARB GPS station. Distance: $2.1 \mathrm{~km}$.

Four sites where the DORIS stations are located between 1 and $3 \mathrm{~km}$ away from the other techniques stations can nevertheless be considered as physically unique sites (Fagard, personal communication). Those are Reykjavik (DORIS and GPS stations $2.4 \mathrm{~km}$ apart), Ny Alesund (DORIS stations $1.6 \mathrm{~km}$ away from the VLBI-GPS observation complex), Metsahovi (DORIS and GPS stations $2.8 \mathrm{~km}$ apart), and Fairbanks (DORIS stations $1 \mathrm{~km}$ away from the VLBIGPS observation complex). Otherwise, stations located within $1 \mathrm{~km}$ from each other were considered as belonging to the same site. With three sites not being considered (Ascension, Guam, and Kourou) and two sites (Hartebeesthoek and Orroral) being split into two sub-sites, we get a total of 56 physically meaningful collocation sites, with position time-series measured for a total of 144 stations.

The three-cornered hat method requires that at least three parallel time-series of measurements with independent errors are available at a given site. Twelve sites provide such data. They are listed in Table 10.

\section{References}

Allan, D. W., Statistics of Atomic Frequency Standards, Proc. IEEE, 54, 221-231, 1966.

Allan, D. W., Time and frequency characterisation, estimation, and prediction of precision clocks and oscillators, IEEE Trans. UFCC, 34, 647654, 1987.

Allan, D. W. and J. A. Barnes, A Modified "Allan Variance" with Increased Oscillator Characterization Ability, Proceedings of the 35th Annual Frequency Control Symposium, 470-475, 1981.

Altamimi, Z. and X. Collilieux, The status of ITRF2004, IAG Symposium Series, 130, Springer-Verlag, P. Tregoning and C. Rizos (eds), 2007 (in press).

Altamimi, Z., C. Boucher, and P. Sillard, New Trends for the Realization of the International Terrestrial Reference System, Adv. Space Res., 30, $175,2001$.

Altamimi, Z., P. Sillard, and C. Boucher, ITRF2000, A new release of the international terrestrial reference frame for Earth science applications, J. Geophys. Res., 107(B10), 2214, 2002.

Altamimi, Z., C. Boucher, and D. Gambis, Long-term stability of the Terrestrial Reference Frame, Advances in Space Research, 36, 342-349, 2005.

Altamimi, Z., X. Collilieux, and C. Boucher, DORIS contribution to ITRF2005, J. Geod., 80, 625-635, 2006.

Blaha, G., Free networks: minimum norm solution as obtained by the inner adjustment constraint method, Bull. Geod., 56, 209-219, 1982.

Blewitt, G. and D. Lavallée, Effect of annually repeating signals on geodetic velocity estimates, paper presented at The Tenth General Assembly of the WEGENER Project (WEGENER 200), San Fernando, Spain, September 18-20, 2000. 
Blewitt, G. and D. Lavallée, Effect of annual signals on geodetic velocity, J. Geophys. Res., 107, B7, ETG 9-1, 2002.

Boucher, C., Z. Altamimi, P. Sillard, and M. Feissel-Vernier, The ITRF2000, IERS Technical Note, 31, 2004.

Collilieux, X., Z. Altamimi, D. Coulot, J. Ray, and P. Sillard, Spectral and correlation analyses of ITRF2005 VLBI, GPS and SLR height residuals: How well do space geodetic techniques agree?, J. Geophys. Res., submitted, 2007.

Coulot, D., Télémétrie laser sur satellites et combinaison de techniques géodésiques. Contribution aux systèmes de référence et applications, PhD Thesis dissertation, Paris Observatory, Jul. 2005.

Ding, X. L., D. W. Zheng, D. N. Dong, C. Ma, Y. Q. Chen, and G. L. Wang, Seasonal and secular positional variations at eight collocated GPS and VLBI stations, J. Geod., 79, 71-81, 2005.

Dong, D., P. Fang, Y. Bock, M. K. Cheng, and S. Miyazaki, Anatomy of apparent seasonal variations from GPS-derived site position time series, J. Geophys. Res., 107, 9-1, 2002.

Feissel-Vernier, M. and K. Le Bail, Spectral characteristics of the measurement of station motion with GPS, IGS 2004-2005 Technical report, Edited by IGS Central Bureau, 2006 (in press).

Feissel-Vernier, M., K. Le Bail, P. Berio, D. Coulot, G. Ramillien, and J. J. Valette, Geocenter motion measured by DORIS and SLR and geophysical evidence, J. Geod., 80, 637-648, 2006.

Ferland, R., J. Kouba, and D. Hutchison, Analysis methodology and recent results of the IGS network combination, Earth Planets Space, 52, 953957, 2000.

Gontier, A.-M., K. Le Bail, M. Feissel, and T. M. Eubanks, Stability of the extragalactic VLBI reference frame, Astron. Astrophys., 375, 661-674, 2001.

Gontier, A.-M., M. Feissel-Vernier, and C. Barache, Paris Observatory Analysis Center OPAR: Report on Activities, January-December 2005, IVS Annual Report, 2005, 256-259, 2006.

Gray, J. E. and D. W. Allan, A method for estimating the frequency stability of an individual oscillator, Proc. 28th Annual Symp. on Frequency Control, May 1974, 243-246, 1974.

Hugentobler, U. and G. Beutler, Measurement of Geocenter Variations With GNSS, American Geophysical Union, Fall Meeting 2005, abstract G31A-02, 2005.

Koot, L., O. de Viron, and V. Dehant, Atmospheric angular momentum time-series: characterization of their internal noise and creation of a combined series, J. Geod., 79, 663-674, 2006.

Langbein, J. and H. Johnson, Correlated errors in geodetic time-series: Implications for time-dependant deformation, J. Geophys. Res., 102, 591-604, 1997.

Le Bail, K., Etude statistique de la stabilité des stations de géodésie spatiale. Application à DORIS, PhD Thesis dissertation, Observatoire de Paris, Dec. 2004.

Le Bail, K., Estimating the noise in space-geodetic positioning. The case of DORIS, J. Geod., 80, 541-565, 2006.

Le Bail, K., M. Feissel-Vernier, J.-J. Valette, and W. Zerhouni, Long term consistency of multi-technique terrestrial reference frames, a spectral approach, IAG Symposium Series, 130, Springer-Verlag, P. Tregoning and C. Rizos (eds), 2006 (in press).

Lindman, H. R., Analysis of variance in complex experimental designs, Edited by W. H. Freeman and Co, San Francisco, 1974.

Ma, C., E. F. Arias, T. M. Eubanks, A. L. Fey, A.-M. Gontier, C. S. Jacobs, O. J. Sovers, B. A. Archinal, and P. Charlot, The International Celestial Reference Frame as realized by Very Long Baseline Interferometry, Astron. J., 116, 516, 1998.

Mangiarotti, S., A. Cazenave, L. Soudarin, and J.-F. Crétaux, Annual vertical crustal motions predicted from surface mass redistribution and observed by space geodesy, J. Geophys. Res., 106, 4277-4292, 2001.

Mao, A., C. G. A. Harrison, and T. H. Dixon, Noise in GPS coordinate times series, J. Geophys. Res., 104, 2797-2816, 1999.

McCarthy, D. D., G. Petit, (eds) IERS Standards (2003), IERS Technical Note, 32, BKG, Frankfurt am Main, Germany, 2004.
McMillan, D. S. and C. Ma, Atmospheric gradients and the VLBI terrestrial and celestial reference frames, Geophys. Res. Lett., 24, 453, 1997.

Meisel, B., D. Angermann, M. Kruegel, H. Drewes, M. Gerstl, R. Kelm, H. Mueller, W. Seemueller, and V. Tesmer, Refined approaches for terrestrial reference frame computations, Adv. in Space Res., 36, 350357, 2005.

Michel, V., G. Roesch, and J. Long, Hartebeesthoek Co-location Survey, Proceedings of the IERS Workshop on site co-location. IERS Technical Note, 33, Edited by W. R. Dick and B. Richter, 34-36, BKG, Frankfurt am Main, Germany, 2005.

Nicolas, J., J.-M. Nocquet, M. van Camp, T. van Dam, J.-P. Boy, J. Hinderer, P. Gegout, E. Calais, and M. Amalvict, Seasonal effect on vertical positioning by Satellite Laser Ranging and Global Positioning System and on absolute gravity at the OCA geodetic station, Grasse, France, Geophys. J. Int., 167, 1127-1137, 2006.

Penna, N. T. and M. P. Stewart, Aliased tidal signatures in continuous GPS height time-series, Geophys. Res. Lett., 30, 2184-2187, 2003.

Percival, D. B., Stochastic models and statistical analysis for clock noise, Metrologia, 40, S289-S304, 2003.

Petrov, L. and J. Boy, Study of the atmospheric pressure loading signal in very long baseline interferometry observations, J. Geophys. Res., 109, B03405, 2004.

Petrov, L. and C. Ma, Study of harmonic site position variations determined by very long baseline interferometry, J. Geophys. Res., 108, B4, ETG 5-1, 2003.

Premoli, A. and P. Tavella, A Revisited Three-Cornered-Hat Method for Estimating Frequency Standards Instability, IEEE Trans. on instrumentation and measurement, 42, 1-10, 1993.

Ray, J. and Z. Altamimi, Evaluation of co-location ties relating the VLBI and GPS reference frames, J. Geod., 79, 189-195, 2005.

Richter, B., W. R. Dick, and W. Schwegmann, (eds) Proceedings of the IERS Workshop on site co-location, Matera, Italy, 23-24 October 2003, IERS Technical Note, 33, 2005.

Soudarin, L. and J.-F. Crétaux, ftp://cddis.gsfc.nasa.gov/doris/products/sinex_series/lcawd/lcawd14_snx_dsc.txt, 2006a.

Soudarin, L. and J.-F. Crétaux, A model of present-day plate motions from 12 years of DORIS measurements, J. Geod., 80, 609-624, 2006b.

Steigenberger, P., M. Rothacher, R. Dietrich, M. Fritsche, A. Ruelke, and S. Vey, Reprocessing of a global GPS network, J. Geophys. Res., 111, B05402, 2003.

Tavernier, G., H. Fagard, M. Feissel-Vernier, K. Le Bail, F. Lemoine, C. Noll, J. Ries, L. Soudarin, J.-J. Valette, and P. Willlis, The International DORIS Service: genesis and early achievements, J. Geod., 80, 403-417, 2006.

Titov, O. and H. Yakovleva, Seasonal variation in radial components of VLBI stations, Astron. and Astrophys. Trans., 18, 593-606, 1999.

Williams S. D. P., Offsets in Global Positioning System time series, $J$. Geophys. Res., 108 (B6), 2310, 2003.

Williams, S. D. P. and P. Willis, Error analysis of weekly station coordinates in the DORIS network, J. Geod., 80, 525-539, 2006.

Williams, S. D. P., Y. Bock, P. Fang, P. Jamason, R. M. Nikolaidis, L. Prawirodirdjo, M. Miller, and D. J. Johnson, Error analysis of continuous GPS position time-series, J. Geophys. Res., 109, B03412, 2004.

Wöppelmann, G., B. Martin-Miguez, M.-N. Bouin, and Z. Altamimi, Geocentric sea-level trend estimates from GPS analyses at relevant tide gauges world-wide, Global and Planetary change, 2007 (in press).

Zhang, J., U. Bock, H. Johnson, P. Fang, S. Williams, J. Genrich, S. Wdowinski, and J. Behr, Southern California Permanent GPS Geodetic Array: error analysis of daily position estimates and site velocities, $J$. Geophys. Res., 102, 18035-18056, 1997.

M. Feissel-Vernier (e-mail: mf.vernier@gmail.com), O. de Viron (e-mail: deviron@ipgp.jussieu.fr), and K. Le Bail (e-mail: karinelebail@gmail.com) 